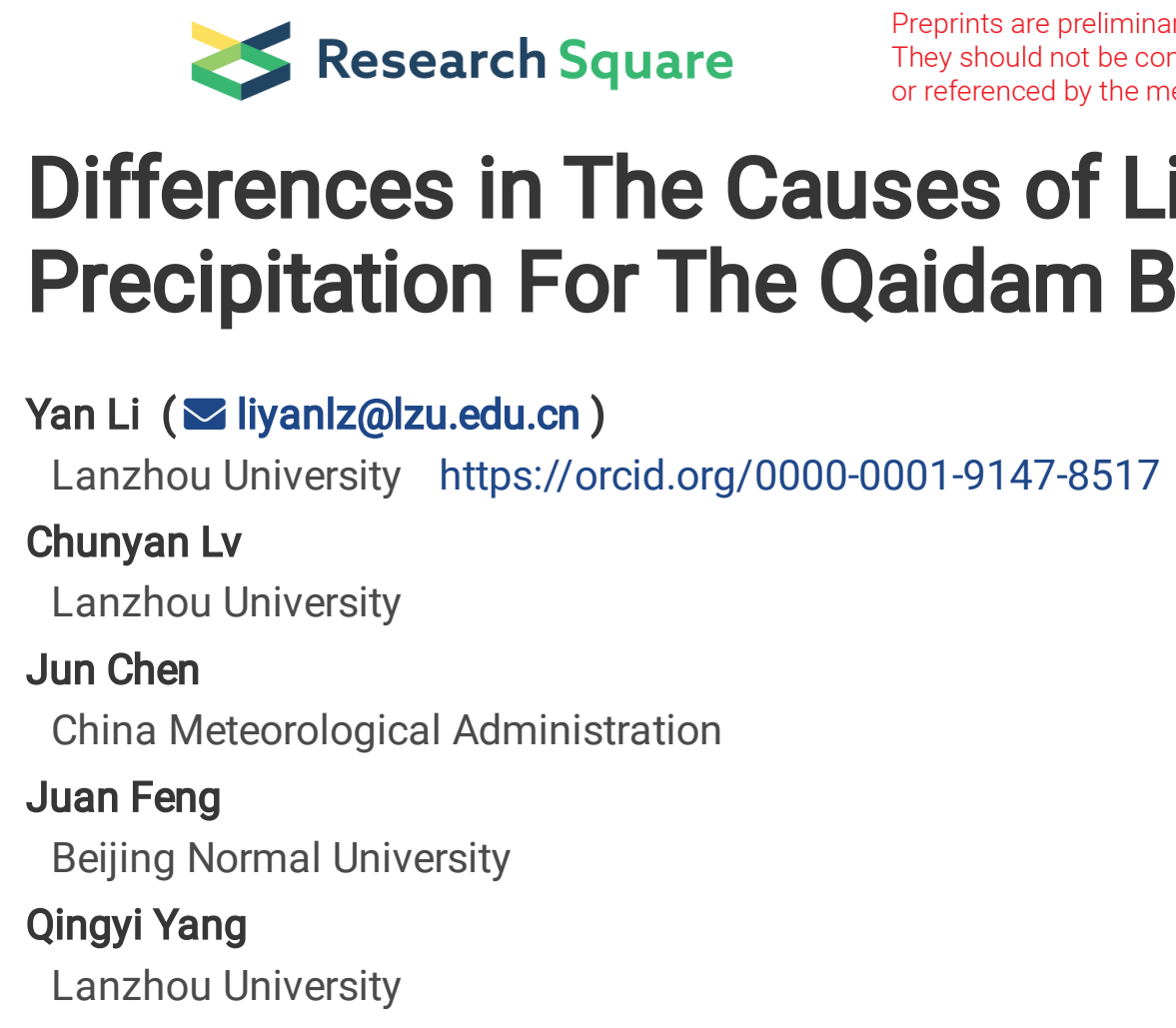

\author{
Yan Li ( $\nabla$ liyanlz@lzu.edu.cn ) \\ Lanzhou University https://orcid.org/0000-0001-9147-8517 \\ Chunyan Lv \\ Lanzhou University \\ Jun Chen \\ China Meteorological Administration \\ Juan Feng \\ Beijing Normal University \\ Qingyi Yang \\ Lanzhou University
}

\title{
Differences in The Causes of Light And Extreme Precipitation For The Qaidam Basin In Summer
}

\section{Research Article}

Keywords: Extreme precipitation, Abnormal atmospheric circulation, Plateau monsoon, Apparent heat source, The Qaidam Basin

Posted Date: November 3rd, 2021

DOl: https://doi.org/10.21203/rs.3.rs-951750/v1

License: (c) (i) This work is licensed under a Creative Commons Attribution 4.0 International License. Read Full License 


\title{
Differences in the causes of light and extreme precipitation for the Qaidam Basin in summer
}

\author{
Yan $\mathrm{Li}^{1}$, Chunyan Lv ${ }^{1,2}$, Jun Chen ${ }^{2}$, Juan Feng ${ }^{3}$, Qingyi \\ Yang ${ }^{1,4}$
}

${ }^{1}$ College of Atmospheric Sciences, Lanzhou University, Lanzhou 730000, China

${ }^{2}$ Tongren Meteorological Bureau, China Meteorological Administration, Guizhou 554300, China

${ }^{3}$ College of Global Change and Earth System Science, Beijing Normal University, Beijing, China

${ }^{4}$ Lanzhou Resources\&Environment Voc-Tech college, Lanzhou 730000, China

\section{Correspondence}

Juan Feng, College of Global Change and Earth System Science (GCESS), Beijing Normal University, Beijing, China.

Email: fengjuan@bnu.edu.cn.

Funding information This work was supported by the National Key Research \& Development (R\&D) Program of China (Grant/Award Number: 2019YFA0606801) and the Naturals Science Foundation of China (41775051). 


\begin{abstract}
The Qaidam Basin (QB) locates over the northeast of the Tibetan Plateau (TP), where precipitation especially extreme precipitation possesses obvious local characteristics compared with that over the whole TP. This study tries to investigate cause of light $(50 \%$ threshold) and extreme (95\% threshold) precipitation in boreal summer in the QB, which is helpful to deepen understanding of the mechanism of precipitation formation in different regions of the TP. The extreme (light) precipitation thresholds in the eastern QB are greater than that in the western QB, with a value of $6 \sim 16 \mathrm{~mm}(2 \mathrm{~mm})$ for most regions. There are two main moisture transport channels for light and extreme precipitation events. One is from the Eurasia and carried by the westerlies, which provides $48.2 \%$ and $55.8 \%$ of moisture for light and extreme precipitation events, respectively. The other moisture transport channel is from the Arabian Sea and the Bay of Bengal, which is transported toward the QB at the joint role of the South Asian summer monsoon and the plateau monsoon, contributing $51.8 \%$ and $44.2 \%$ of moisture for light and extreme precipitation events, respectively. The stronger moisture transport to precipitation mostly attributes to the enhanced moisture influxes from the western and southern boundaries. Additionally, the weaker moisture outflux across the eastern boundary is also responsible for the extreme precipitation. The circulation characteristics shows that, the precipitation in the QB has a closely relationship with the weak ridge over the Caspian Sea and Aral Sea, the enhanced South Asian summer monsoon and plateau monsoon, which are conducive to the moisture transport from the Eurasia and low-latitudes toward the QB. The meridional circulation enhances, meantime the westerly jet stream splits into east- and west-branch, and the south Asian high (SAH) strengthens, which are beneficial for the stronger convective motion. Especially, the trough in the northwest of the QB and the more significant east- and
\end{abstract}


west-branch structure of westerly jet are the main circulation characteristics for the extreme precipitation events. Further analysis reveals that the apparent heat source over the QB is contributed to more synchronous moisture transport around the TP and its surrounding areas for light precipitation events, while the apparent heat source enhances 1 day prior to moisture transport from the east part region of the South Asian summer monsoon to around the eastern TP for extreme precipitation events. Meantime, the apparent heat source triggers an abnormal cyclone over the TP which can positively strength the local convective motion. Such abnormal configuration of atmospheric circulation and the influence of apparent heat source can explain the difference in cause of precipitation with different magnitude to a great extent in the QB.

Key words: Extreme precipitation, Abnormal atmospheric circulation, Plateau monsoon, Apparent heat source, The Qaidam Basin

\section{Introduction}

The Qaidam Basin (QB), as the largest cold arid region with high elevation in China, is located at the northeast of the Tibetan Plateau (TP) and the northwest China (shown in Fig. 1a), far from the ocean, with mainly arid climate. As with rich Salt Lake mineral resources, the QB is known as "Cornucopia", an important regional energy strategy in China, and is classified as the first batch of national circular economy experimental areas. Under the background of the climate change, the QB has experienced two periods with relatively cold period before 1987 and relatively warm period after 1987 (Shen et al.,2016). The annual mean temperature, maximum temperature, and minimum temperature have increased in the past, with a higher increased trend than that in the TP, and even the global. Associated with global warming, there are more frequent, more intense climate extremes (Huang et al., 2021), so as in the QB the warming trend can 
also affects the local hydrological recycle. In addition, lag behind warming, it has happened that the climate changes from warm dry to warm wet as at the beginning of $21^{\text {st }}$ century. The precipitation and precipitation days increase, and the increased magnitude in the eastern QB is larger than that in the western QB (Shen et al., 2016).

Changes in precipitation characteristics over the TP have been investigated in previous studies. Chen et al. (2015) and Zhang et al. (2019) pointed out a marked precipitation pattern as precipitation is increasing over the northern TP while decreasing over the southern TP. Some studies also suggested there are a wetting and drying trend over the northwestern and southeastern TP, respectively (Cuo et al., 2013; Gao et al., 2015). These results indicate the precipitation pattern in different parts of the TP are various as influences by different atmospheric systems. The northern TP is mainly influenced by the westerlies while the southern TP is dominated by the Asian summer monsoon system, including the south Asian high (SAH) and the subtropical westerly jet as the crucial components (Yao et al., 2013). Wei et al.(2014,2015) pointed out a weak Indian summer monsoon associated with less rainfall over India corresponds to less condensation heat release and anomalous cooling in the upper troposphere over the northern Indian peninsula which stimulates negative height anomalies to its northwest and positive height anomalies to its northeast in the upper troposphere, causing a eastward shift of the SAH with its center over the TP and the formation of an anomalous anticyclone over the eastern TP. Wei et al.(2017) also suggested the southeastward shift of SAH associated with a weak Indian summer monsoon is responsible for the southeastward shift of the westerly jet, which produces anomalous updrafts (downdrafts) over the western (eastern) westerly jet region. Besides, atmosphere heat source indicating the diabatic heating in the atmosphere is one of key factors that leads to the change of large-scale circulation near the TP. Wu et al. (1997) revealed that strong 
sensible heat transport near the surface of the TP in spring and summer triggers positive vorticity in the near surface and negative vorticity in the upper level over the TP, which causes the air mass converged into the plateau in low level and the air mass diverged from the plateau in upper level, thereby affecting and regulating the atmosphere circulation in the TP and its adjacent areas, as well as the Asian monsoon activity, similar to study of Zhao and Chen (2001).

The moisture transport and moisture origins are important for precipitation in the TP. Lei and Zhou (2012) identified the moisture transport originating from the Indian Ocean and the Bay of Bengal dominates the summer precipitation over the southeastern TP. Zhang et al. (2019) showed the region ranging from the TP to Europe dominated by westerlies provides $38.9 \%$ of the precipitation moisture for the northern TP, and the region ranging from the TP to the Indian Ocean and Indochina dominated by the Asian monsoons provides $51.4 \%$ of precipitation moisture for the southern TP. And for the central-western TP, the increased precipitation is mainly attributed to the strengthened moisture transport from the Indian Ocean and the intensified local moisture recycling (Zhang et al., 2017). Above results indicate different parts the TP are controlled by different weather systems, and the moisture contributions are unlike from different areas to the precipitation of different parts the TP.

Recent research shows that the occurrence of extreme weather and climate event has been significantly increased with global warming (Yu et al., 2018; Li et al., 2020). The warming climate results in an enhancement in evaporation and atmospheric moisture content, which leads to the increase of total precipitation and heavy precipitation in turn (Trenberth 1999; Trenberth et al., 2003; Allan and Soden 2008). Extreme precipitation is an important part of weather and climate events, which can cause extraordinary damage to the environment, society, and economy (Fu et al., 2013; Zhou et al., 2013; 
Zhang et al.,2019). Based on theory and numerical models, it is claimed that the heavy precipitation increases more than total precipitation (Shiu et al., 2012; Trenberth et al., 2003), which implicates that there must be a decrease in relatively weaker precipitation events (Trenberth et al., 2003). That is, the heavy precipitation increases at the cost of light precipitation. The trends in the intensity of light precipitation events are opposite to the frequency of light precipitation events, which is possibly associated with light precipitation shifts toward heavier precipitation, making the frequency of light precipitation events decreases consequently (Wen et al., 2016; Ma et al., 2015; Jiang et al., 2014). Some scholars have already studied the variation of extreme precipitation and light precipitation in different regions of China (Zhai et al., 2005; Fu et al., 2013; Feng et al., 2007; Jiang et al., 2014; Ma et al., 2015), but there are few studies concentrating on extreme precipitation and light precipitation over the $\mathrm{TP}$, so as in the QB (You et al.,2008).

To summarize, despite some progresses have been made on the changes of precipitation, and corresponding moisture transport and atmospheric circulation over the TP, such work for the QB solely have not been systematically studied before. Especially, as the regional characteristics of the precipitation in different parts of the $\mathrm{TP}$, it is necessary to focus on the light precipitation and extreme precipitation in the QB, respectively. According to the CN05.1 precipitation data (Wu et al., 2012), we investigate the change in the precipitation of the whole TP and the QB. The mean annual precipitation values of the QB and TP are $197.13 \mathrm{~mm} \cdot \mathrm{yr}^{-1}$ and $409.80 \mathrm{~mm} \cdot \mathrm{yr}^{-1}$ during 1981-2017, respectively. The annual precipitation time series also shows different change trends with a strong increased trend of $9.51 \mathrm{~mm} \cdot$ decade $^{-1}$ significant at the 0.01

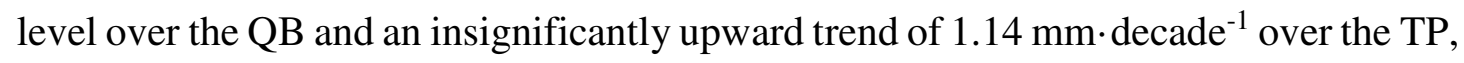
and the correlation coefficient of precipitation between these two regions is 0.228 
(Fig.1b). These results suggest that the QB and TP show completely different precipitation variation characteristics, highlighting the significance to study the regional characteristics for the precipitation in the TB.

Hence, focusing on the characteristics and cause of precipitation in the QB is not only of greatly scientific and practical significance for both natural and managed ecosystems in such arid region, but also beneficial to further understanding of the physical mechanism for regional precipitation over the TP. The annual precipitation in the QB is usually less than $220 \mathrm{~mm}$ (Supplementary Fig. 1a), with summer precipitation accounting for more than $70 \%$ of annual precipitation in western QB and less than $60 \%$ of annual precipitation in eastern QB (Fig. 1c), which indicates the majority of precipitation of the QB occurs in boreal summer. Thereby, this study focuses on the boreal summer season (June, July and August) for the precipitation. The purpose of this study is to address and discuss the following questions: (1) What are the main causes in the atmospheric circulation inducing the different types of precipitation in the QB? (2) How does atmospheric heat source influence moisture transport and convective activity in light and extreme precipitation events? Addressing such issues is beneficial for deep understanding of the physical mechanism of summer precipitation as well as their prediction in arid area of China.

The remainder of this paper is organized as follows: The data and methods are introduced in section 2. The characteristic of light and extreme precipitation over the QB and the corresponding moisture transport are described in section 3. The atmospheric circulation cause and response of precipitation to atmospheric heat source are analyzed in detail in section 4 and section 5, respectively. Finally, summary and discussion are illustrated in section 6.

\section{Data and methods}




\subsection{Data}

A daily precipitation dataset of ten meteorology stations during 1981-2017 in the QB is used to analyze the characteristics of precipitation, which is obtained from local Weather Bureau. Fig. 1c shows the specific geographic location of these meteorology stations, including Mang Ya, Leng Hu, Xiao Zaohuo, Da Chaidan, Ge Ermu, Nuo Muhong, De Lingha, Du Lan, Wu Lan, and Cha Ka. Ten stations are evenly distributed, indicating the data is representative of weather and climate in the QB. Additionally, to test the difference of precipitation between in the QB and TP, the daily China regional grid observation precipitation data set- CN05.1 is used, with a horizontal resolution of $0.25^{\circ}$ latitude by $0.25^{\circ}$ longitude. This data is based on the observation data of more than 2,400 stations in China and established by interpolation using the "anomaly approximation" method, which has been widely used in modeling test and precipitation analysis (Hsu et al., 2016). Finally, the reanalysis data, including geopotential height (GPH), relative humidity, and wind $(u, v, w)$ at 17 isobaric (from $1000 \mathrm{hPa}$ to $10 \mathrm{hPa}$ ), specific humidity at 8 isobaric (from $100 \mathrm{hPa}$ to $300 \mathrm{hPa}$ ) during 1981-2017 are provided by the NCEP/NCAR, with a horizontal resolution of $2.5^{\circ}$ latitude by $2.5^{\circ}$ longitude. The topographic data from the Global Land One-kilometer Base Elevation (GLOBE) project of ETOPO2v2 can be obtained at https://www.ngdc.noaa.gov/mgg/topo/topo.html.

\subsection{Analysis Methods}

\subsubsection{The definition of light and extreme precipitation events}

According to the definition of extreme precipitation (Zhai et al., 2003), the day with daily precipitation equal to or greater than $0.1 \mathrm{~mm}$ is regarded as a precipitation day. For each meteorological station, the precipitation of all precipitation days is arranged in ascending order and the $95^{\text {th }}$ percentile value of the precipitation sequence is then 
taken as the extreme precipitation threshold. Similarly, the $50^{\text {th }}$ percentile value of the precipitation sequence is taken as the light precipitation threshold (Wen et al., 2016). When the daily precipitation of at least $1 / 3$ continuous stations of the total meteorological stations exceeds the extreme (light) precipitation threshold of the station, the extreme (light) precipitation event is considered. According to this criteria, we picked out 27 extreme precipitation events which all last only one day and 281 light precipitation events including 231 events, 47 events, 2 events and 1 events lasting 1day, 2 days, 3 days and 4 days in boreal summer in the QB, respectively.

\subsubsection{Moisture transport and contribution}

To evaluate the important impacts of moisture transport on the QB precipitation, the vertically integrated horizontal moisture flux was calculated following by

$$
Q=\frac{1}{g} \int_{300 h P a}^{p_{S}} q \vec{V} d p
$$

Where $q, g, p_{s}, \vec{V}$, and $Q$ represent specific humidity, gravity acceleration, surface pressure, horizontal wind, and moisture flux, respectively. The vertically integrated of the moisture flux was preformed from surface pressure to $300 \mathrm{hPa}$ due to the air above $300 \mathrm{hPa}$ is highly dry and contributes little to the moisture transport process (Sun et al., 2014). Besides, the horizontal moisture flux divergence integrated from the surface to $300 \mathrm{hPa}$ can be expressed as

$$
\nabla \cdot Q=\frac{1}{g} \int_{300 h P a}^{p_{s}} \nabla \cdot(q \vec{V}) d p
$$

In general, the net moisture flux for target region is most determined by the sum of moisture flux across the four boundaries (refer to western, southern, eastern and northern boundaries, respectively). The vertically integrated of moisture flux across the four boundaries were computed according to Sun et al. (2014), where positive values represent moisture influx and negative values represent outflux. 
We also use the HYSPLIT_4 model to quantitatively evaluate the contribution of each moisture transport to precipitation in the $\mathrm{QB}$, and the detailed description of the HYSPLIT_4 model can be found in Stein et al. (2016). In this study, we select the QB $\left(35^{\circ} \mathrm{N}-40^{\circ} \mathrm{N}, 90^{\circ} \mathrm{E}-100^{\circ} \mathrm{E}\right)$ with $2.5^{\circ} \times 2.5^{\circ}$ grid resolution as the study region, and the starting simulated height is $3000 \mathrm{~m}$ due to the altitude of the QB. As a result, there are 15 trajectory starting locations at initial time. Then backward trajectory of these trajectories at starting locations is retrieved and the total run time is 14 days due to time that all particles arrived at their sources. The model output is executed every 6 hours and the meteorology data along trajectory is obtained by interpolating. Finally, we run a trajectory cluster analysis for a series of trajectories and get the number of cluster (see user guide which can be founded in https://ready.arl.noaa.gov/HYSPLIT.php). According to the specific humidity of all trajectory endpoints, we can calculate the moisture contribution of each cluster as

$$
Q_{s}=\frac{\sum_{1}^{m} q_{\text {last }}}{\sum_{1}^{n} q_{\text {last }}} \times 100 \%
$$

$\mathrm{Q}_{\mathrm{s}}$ is the moisture contribution, $\mathrm{q}_{\text {last }}$ is the specific humidity of trajectory endpoint, $\mathrm{m}$ is the number of trajectories in the cluster (henceforth moisture channel), and $\mathrm{n}$ is the total number of trajectories.

\subsubsection{Apparent heat source and apparent moisture sink}

Following Yanai et al. (1973), the atmospheric apparent heat source $\left(Q_{1}\right)$ and apparent moisture sink $\left(Q_{2}\right)$ can be expressed as

$$
\begin{gathered}
Q_{1}=C_{p}\left[\frac{\partial T}{\partial t}+\vec{V} \cdot \nabla T+\left(\frac{p}{p_{0}}\right)^{\kappa} \omega \frac{\partial \theta}{\partial p}\right. \\
Q_{2}=-L\left[\frac{\partial q}{\partial t}+\vec{V} \cdot \nabla q+\omega \frac{\partial q}{\partial p}\right]
\end{gathered}
$$

where $c_{p}$ denotes the specific heat at constant pressure, $T$ is the air temperature, $t$ is the time, $\vec{V}$ is the horizontal wind velocity, $\omega$ is the vertical velocity, $p$ is the 
pressure, $\theta$ is the potential temperature, $\mathrm{p}_{0}=1000 \mathrm{hPa}, \mathrm{q}$ is the specific humidity, $\mathrm{L}$ is the latent heat of condensation, and $\kappa=\frac{R}{C_{p}}$ with $R$ is the gas constant. Here $Q_{1}$ denotes the total diabatic heating, including radiation, latent heat and surface heat flux, and subgrid-scale heat flux convergence; $Q_{2}$, on the other hand, represents the latent heat due to condensation or evaporation processes and sub grid-scale moisture flux convergence (Yanai et al., 1973). The $\mathrm{Q}_{1}$ and $\mathrm{Q}_{2}$ integrated from $1000 \mathrm{hPa}$ to $10 \mathrm{hPa}$ are the whole column apparent heat source $\left(<Q_{1}>\right)$ and apparent moisture sink $(<$ $\left.\mathrm{Q}_{2}>\right)$

\subsubsection{Quantitative indices of atmospheric circulation systems affecting}

\section{precipitation}

The evolution of plateau monsoon is essential to the weather and climate processes over the TP and the northwest China (Zhou et al., 2016; Fang et al., 2016). Based on the circulation characteristic of plateau monsoon, the plateau monsoon index was defined using the averaged divergence over $30^{\circ} \mathrm{N}-35^{\circ} \mathrm{N}, 80^{\circ} \mathrm{E}-100^{\circ} \mathrm{E}$ at $600 \mathrm{hPa}(\mathrm{Zhou}$ et al., 2015). Following the definition of divergence of the plateau monsoon index (DPMI), the negative values indicate there is convergence of wind field near the surface plateau in summer, and the larger the absolute values, the stronger the plateau summer monsoon.

The South Asian summer monsoon and SAH have a significant impact on precipitation in China through affecting the moisture transport and upward motion $(\mathrm{Li}$, et al., 2019). To reflect the variation of the South Asian summer monsoon and SAH during the period of precipitation over the QB, the South Asian summer monsoon index and SAH index (SAHI) were used. The South Asian summer monsoon index is a timemean zonal wind shear between $850 \mathrm{hPa}$ and 200hPa (Webster and Yang, 1992), i.e., U850-U200, averaged over south Asian from the equator to $20^{\circ} \mathrm{N}$ and from $40^{\circ} \mathrm{E}$ to 
$110^{\circ} \mathrm{E}$ (henceforth WYI). The SAHI is defined as the weighted sum of the GPH of all grid points which is greater than $12520 \mathrm{gpm}$ in the northern hemisphere at $200 \mathrm{hPa}$ (Zhang et al., 2016). Here the SAHI represents not only the intensity but also the area controlled by the SAH.

We also calculated westerly jet index (WJI) and westerly circulation index (WCI) in order to investigate how do the westerly affect the precipitation in the QB. The WJI is defined as zonal wind averaged over $35^{\circ} \mathrm{N}-45^{\circ} \mathrm{N}, 50^{\circ} \mathrm{E}-105^{\circ} \mathrm{E}$ at $200 \mathrm{hPa}$ (Liao et al., 2018), and the WCI refers to the difference of GPH at $500 \mathrm{hPa}$ between $35^{\circ} \mathrm{N}$ and $55^{\circ}$ $\mathrm{N}$ (Rossby, 1939). In addition, the index of low pressure system intensity (henceforth LPSI) in the QB was considered, which is vorticity averaged over $35^{\circ} \mathrm{N}-40^{\circ} \mathrm{N}, 90^{\circ} \mathrm{E}-$ $100^{\circ} \mathrm{E}$ at $700 \mathrm{hPa}$.

\section{Precipitation and corresponding moisture transport}

\subsection{Spatial distribution of precipitation}

Fig 2a-b show the percentage of total light (extreme) precipitation to summer precipitation. It is shown that total light precipitation accounts for $8 \% \sim 22 \%$ of summer precipitation while total extreme precipitation accounts for $2 \%$ 14\% of summer precipitation, which indicates both light precipitation and extreme precipitation are crucial for summer precipitation in the QB. The rainfall decreases from the western to eastern QB for light precipitation events, and decreases from the central QB to the western and eastern QB for extreme precipitation events, which shows the physical processes causing two types precipitation events are different. It is obvious that the values of the ratio of total light precipitation to summer precipitation are greater than that of the ratio of total extreme precipitation to summer precipitation in most region except for the south-central $\mathrm{QB}$, indicating the light precipitation contributes more to summer precipitation in the $\mathrm{QB}$, even arid region of China. As the precipitation occurs 
infrequently in the QB and total precipitation is greatly less than that in eastern China, the ability to cope with extreme precipitation in the QB is weaker than that in eastern China. Once extreme precipitation happens, more serious damage will be brought to the $\mathrm{QB}$, highlighting significance of more attention to extreme precipitation here. Light precipitation refers to the precipitation with relatively small magnitude, accounting for nearly one-fifth of total summer precipitation in the QB, which could reflect the basic precipitation characteristic in a region to some extent.

The light and extreme precipitation thresholds for each meteorological station, shown in Fig. 2c-d, were computed separately. The light precipitation thresholds for most regions are less than $2 \mathrm{~mm}$, only exceeds $2 \mathrm{~mm}$ over stations locating at the eastern QB. The extreme precipitation thresholds in the eastern QB are greater than that in the western QB. The maximum of extreme precipitation thresholds is over $16 \mathrm{~mm}$ in De Lingha station and Du Lan station, and the minimum of the extreme precipitation thresholds is less than $6 \mathrm{~mm}$ in the central-western QB. The pattern of summer extreme precipitation thresholds is in highly accordance with the spatial distribution of summer precipitation in the QB (Supplementary Fig. 1b), indicating that the region with higher precipitation in summer is also the area where extreme precipitation occurs with higher possibility.

\subsection{Moisture transport}

To investigate the relationship between moisture transport and precipitation in the QB, we show the vertically integrated moisture flux and moisture flux divergence of two types of precipitation events, as shown in Fig. 3. For light precipitation events, there are two main moisture channels. One moisture channel is from the black Sea, Caspian Sea and Aral Sea and then turns southeastward to affect the study region, which is the main moisture transport affecting precipitation in the QB. Besides, part of the 
moisture originating from these region turns southward and combines with the moisture from the Indian Ocean, which is the south branch moisture channel affecting the QB and carrying moisture from Arabian Sea and the Bay of Bengal northward subsequently. But this moisture channel is slight and only affects the southern QB (Fig. 3a). Thereby, we can conclude that the moisture transport affecting the QB mostly come from the west which is most influenced by the westerlies, which can also be found in Yao et al. (2013) and Zhang et al. (2019). Similar moisture channels can be also exhibited when precipitation occurs in the Tarim Basin in summer (Huang et al., 2015). This result is also further supported by computing the moisture transport across the four boundaries of the QB (Fig. 5b). For extreme precipitation events, the moisture channels agree with that of the light precipitation events, but the magnitude of moisture carried by the south branch moisture channel increases obviously, bringing more moisture to the $\mathrm{QB}$, and the north branch of moisture transport has increased slightly compared with that of light precipitation events (Fig. 3b).

From Fig 3c and Fig. 3d, the moisture carried by the south branch moisture channel which is from the Eurasia instead of Arabian Sea and the Bay of Bengal is the main reason to trigger light precipitation in the QB. But the moisture carried by the south branch moisture channel which is from the Arabian Sea and the Bay of Bengal instead of the Eurasia is the main reason to induce extreme precipitation in the QB. Based on above analysis, it is concluded that moisture affecting the relatively weaker precipitation mainly comes from the Eurasia but mainly comes from the low latitude ocean for extreme precipitation.

In order to verify the moisture transport channels and origins of two types precipitation event, the 14 days backward trajectory model based on Lagrange method is used. As shown in Fig.4a, there are four moisture channels for light precipitation 
events. The moisture of Eurasia channel (marked as 1A and 1B, respectively) origins from the Mediterranean and the East European Plains which provide 37.1\% and 7.4\% of light precipitation moisture for the QB. The Arabian Sea-the Bay of Bengal channel (marked as 2) is clustered by Somali jet stream and cross-equatorial flow, which are converged in the south of the Indian Peninsula and then transported northeastward to the QB though the Indian Peninsula and the TP. This channel provides 51.8\% of lightly precipitated moisture for the QB. The eastern channel (marked as 3) originates from easterly flow transport in Loess Plateau providing only $3.7 \%$ of lightly precipitated moisture for the QB. The channels 1A and 1B are from upper level, while the channels 2 and 3 do the opposite, from low level (Fig.4c).

There are five moisture channels for extreme precipitation events. The moisture of Eurasia channel (marked as 1A, 1B and 1C, respectively) origins from the Black Sea and West Siberian plain which provide $37.7 \%, 2.1 \%$ and $11.7 \%$ of extremely precipitated moisture for the QB. The Arabian Sea-the Bay of Bengal channel (marked as 2) is similar to light precipitation events and provides $44.2 \%$ of extremely precipitated moisture. The eastern channel that turns from the west to the east around the Loess Plateau (marked as 3) originates from westerly flow transport in the north of the QB providing only 5.2\% of extremely precipitated moisture (Fig.4b). Similar to that during light precipitation events, the channels $1 \mathrm{~A}, 1 \mathrm{~B}$ and $1 \mathrm{C}$ are from upper level, while the channels 2 and 3 are from low level during the period of extreme precipitation (Fig.4d).

In fact, as the endpoint of eastern channels all could be lie in the Eurasia even if we calculate more than 14-day backward trajectory for these two types event, it is feasible to classify the eastern channels to the Eurasia channel. Thereby, two moisture channels could be concluded for precipitation events in general, i.e., the Eurasia channel (called 
as the north branch moisture channel before) and the Arabian Sea-the Bay of Bengal channel (called as the south branch moisture channel before). The contribution from the Eurasia channel is $48.2 \%$ and $55.8 \%$ for light and extreme precipitation, respectively. The contribution from the Arabian Sea-the Bay of Bengal channel is 51.8\% and $44.2 \%$ for light and extreme precipitation events, respectively. It is indicated the moisture source from the Eurasia dominated by the westerlies have contributed more precipitated moisture for extreme precipitation, while the moisture source from the Arabian Sea and the Bay of Bengal dominated by the monsoons have dedicated more precipitated moisture for light precipitation. Besides, the journey of trajectory endpoints in Eurasia of extreme precipitation is shorter and more northward, indicating the zonal wind is weak and the meridional circulation is more significant compared with that during light precipitation events.

Fig. 3 also displays the vertically integrated moisture flux convergence. For two types of precipitation events, there is obvious moisture flux convergence in the QB and its surrounding areas. There is anomalous moisture flux convergence in the QB during the period of light precipitation, while there is only anomalous moisture flux convergence in the central-eastern QB for extreme precipitation events, there is anomalous moisture flux divergence in the western QB at this time. What is the reason that there is the abnormally poor moisture in the western QB but the increased precipitation during the period of extreme precipitation?

According to the statistical analysis of 27 extreme precipitation events (Supplementary fig. 2), it was found that extreme precipitation mainly occurred in the central-eastern QB. In addition, Moisture conditions and convective activities are necessary conditions for the occurrence of precipitation, therefore, it can also cause heavy precipitation if there is strong convective activity with little moisture. Finally, 
the occurrence of heavy rainfall is generally concentrated within a few hours, the daily average data used in this study will weaken the signal of moisture convergence during heavy rainfall. Therefore, the anomalous moisture flux divergence in the western QB here does not represent there is not enough moisture to precipitated during extreme precipitation. It also can be seen that there is an obvious abnormal southerly wind convergence in the eastern $\mathrm{QB}$, which shows that the moisture convergence is significant during the period of extreme precipitation. Meantime, there is an abnormal cyclonic wind field surrounding the TP, which can transport moisture originating from the Arabian Sea and the Bay of Bengal northward and eventually converge in the QB. This cyclonic wind field is closely related to the plateau monsoon. Chen et al. (2012) revealed that the TP is the "re-channel-station" for the southwesterly flow originating from the Arabian sea and the Bay of Bengal, which makes the moisture transporting toward the QB though east side of the TP, then affecting the precipitation of the studied region. Such role of re-channel-station of the TP is also beneficial to the precipitation over northwest and east of China (Chen et al., 2012).

To further evaluate the relative role of low-, middle- and upper-level moisture on the QB precipitation, the vertical structure of moisture transport was computed, as shown in Fig.5. We divided the whole air column into low (from surface pressure to700hPa), middle $(700 \mathrm{hPa}-500 \mathrm{hPa})$, and upper $(500 \mathrm{hPa}-300 \mathrm{hPa})$ layers. Because the altitude of the QB is above $2600 \mathrm{~m}$, as illustrated in Fig. 1a, there is no moisture transport across southern boundary at low layer.

The main moisture influxes to the QB for summer climate state are from the western and northern boundaries, and the main moisture outflux is from the eastern boundary (Fig.5a). The moisture transport across western boundary is mainly concentrated in the upper layer and decreases from upper level to the surface. As the altitude decrease to 
$700 \mathrm{hPa}$, the eastward moisture transport turns back to the westward. The moisture transport across northern boundary is concentrated in middle- and low-level, with the largest value of southward moisture in low-level. In the middle layer, the southward moisture transport is less than that in the low layer, while in the upper layer, the southward moisture is highly weak due to low humidity and still maintains southward direction. It can be seen that the moisture transport across the southern boundary is little in middle and upper layer, which is much smaller in magnitude than that across the other three boundaries because of the barrier role of the TP, and the northward moisture transport turns back to the southward as the altitude increases. The moisture transport across eastern boundary is eastward and increases from low level to upper level.

For light precipitation events, the main moisture influxes are also from the western and northern boundaries. The moisture transport influx across southern boundary is small, while it is significantly stronger compared with the summer climate state, and the main moisture outflux is still from the eastern boundary (Fig.5b). There are four aspects illustrating the main characteristics about the moisture transport across the western, northern, southern and eastern boundaries. Firstly, the moisture transport across western boundary is concentrated in the upper layer and decreases from upper level to the surface. Secondly, the moisture transport across northern boundary is concentrated in middle- and low-level, and the moisture transport in the upper layer is northward instead of southward which is opposite to that of the middle and low layers. Thirdly, the moisture transport from the southern boundary increases from middle to upper layer and remains smaller in magnitude than that from the other three boundaries. Finally, the moisture transport across eastern boundary is eastward and increases from low level to upper level, which is consistent with summer climate state but with larger values. 
As is shown in Fig.5c, the main moisture influx (outflux) for extreme precipitation events is from western (eastern) boundary. Compared with that in summer climate state, the moisture transport from northern boundary is obviously weaker, while the moisture transport from southern boundary is significantly stronger. The moisture transport from western boundary still increases from low layer to upper layer and the total moisture transport is $98.04 \mathrm{~kg} . \mathrm{s}^{-1}$, which is larger compared with $85.12 \mathrm{~kg} . \mathrm{s}^{-1}$ for light precipitation events. In low and middle layers, the magnitude of moisture transport is larger than that of light precipitation events, while the situation is opposite at upper level. The total moisture influx from northern boundary is $45.14 \mathrm{~kg} . \mathrm{s}^{-1}$, which is less than that light precipitation events with $86.45 \mathrm{~kg} . \mathrm{s}^{-1}$, because the northward (southern) moisture transport in upper (middle) level is far larger (less) than that light precipitation events, and the southward moisture transport in low level is slightly larger that light precipitation events. And the moisture transport from the southern boundary increases in upper layer compared with light precipitation events. Besides, the moisture transport across eastern boundary is westward in middle and low levels which is different from that in summer climate state and light precipitation events, while is eastward at upper level, and the total eastward moisture transport is $52.84 \mathrm{~kg} \cdot \mathrm{s}^{-1}$.

From the above analysis we can conclude that the stronger moisture transport from western and southern boundaries, and may significantly contribute to the occurrence of precipitation especially extreme precipitation in the QB. And the weaker eastward moisture transport across eastern boundary is also the reason making the occurrence of extreme precipitation in the QB. For the summer climate state and two types precipitation events, the low and middle layers, especially the low layer, are net moisture influx layers, while the upper layer is the net moisture outflux layer. The total net moisture influxes in the whole air column are $50.74 \mathrm{~kg} . \mathrm{s}^{-1}, 67.54 \mathrm{~kg} . \mathrm{s}^{-1}$ and 133.21 
$\mathrm{kg} . \mathrm{s}^{-1}$ for summer climate state, light precipitation events and extreme precipitation events, respectively. As a result, the total net moisture influx of extreme precipitation events is $262.64 \%$ (197.23\%) of that of summer climate state (light precipitation events).

\subsection{Convective activity}

Besides the strengthened net moisture inputs, proper meteorological conditions are needed to facilitate the moist air to be precipitated out. In this section, we analyze convective activity when precipitation occurs in the QB. The vertical structure of $\omega$ and horizontal wind divergence averaged over $35^{\circ} \mathrm{N}-40^{\circ} \mathrm{N}, 90^{\circ} \mathrm{E}-100^{\circ} \mathrm{E}$ for summer climate state and two types precipitation events are shown in Fig. 6.

It is observed that in summer the $\omega$ is less than zero from low level to upper level in the QB, indicating the upward motion dominates here which is a direct result of the thermal effect over the TP (Ye et al., 1957). Compared with summer climate state, the upward motion is stronger when precipitation especially extreme precipitation happens in the QB. In addition, for two types precipitation events, there is obvious horizontal wind convergence below $550 \mathrm{hPa}$ and horizontal wind divergence above $550 \mathrm{hPa}$ over the QB, which is not obvious in summer climate state. The difference of the intensity of horizontal wind divergence from surface to upper level between light and extreme precipitation events indicates the magnitude of net moisture influx is different. The stronger of the horizontal wind convergence in low level and divergence in upper level, the more moisture is converged and lifted in the QB.

\section{Atmospheric circulation cause of the precipitation}

\subsection{Atmospheric circulation characteristics}

To further understand the causes of the moisture transport and the precipitation of two types precipitation events, we investigated the atmosphere circulation that are associated with the summer precipitation in the QB (Fig. 7). As shown in Fig.7a, the 
light precipitation is closely related to a positive GPH anomaly over the west Siberian and a negative GPH anomaly over the QB and the adjacent area at 500hPa. Consequently, there is anomalous pressure gradient over mid-high latitudes inducing anomalous northerly wind southward that can affect the QB. Additionally, a weak ridge lying over the Caspian Sea and Aral Sea, makes the northwesterly flow prevailing at northwest of the QB, which is consistent with the moisture transport from the northwest of the QB (Fig. 3b). A low pressure lying over the west coast of the Bay of Bengal carries a large amount of warm and moist air northward, which is responsible for the precipitation in the QB together with the relay role of the TP. The atmospheric circulation at $200 \mathrm{hPa}$ is also analyzed to investigate the characteristics of upper-level westerly jet and SAH (Fig. 7b). The area enclosed by 12520gpm isoline (main body of the $\mathrm{SAH}$ ) is mainly located at southern Asian, with the center locating near $27^{\circ} \mathrm{N}, 90^{\circ}$ $\mathrm{E}$ and its GPH value is above $12560 \mathrm{gpm}$. The northern flank of the SAH is the subtropical westerly jet stream which lies near $40^{\circ} \mathrm{N}$. It is observed that the westerly jet stream splits into east- and west-branch over the Eurasia when light precipitation appears in the QB, with a weaker west branch of westerly jet lying over Caspian Sea and a stronger east branch of westerly jet lying over the north of QB which shifts eastward slightly compared with climatological summer westerly jet stream. In this case, the QB is located at southern flank of the westerly jet and northern flank of the SAH in upper troposphere, with anticyclonic circulation corresponding to divergence which is conducive to the occurrence of upward motion in the QB.

There are a positive GPH anomaly which extends northeastward from the eastern of Iranian plateau to the Northeast China Plain and a negative GPH anomaly which extends from the north of the QB to the northern of the Bay of Bengal during the extreme precipitation period (Fig. 7c). The intensity of GPH anomaly is stronger 
compared with that of light precipitation events, which leads to a stronger pressure gradient anomaly over mid-high latitudes, then induces stronger anomalous northerly wind affecting the QB. The intensity of the weak ridge over the Caspian Sea and Aral Sea enhances, and a new trough appears in the northwest of the $\mathrm{QB}$, inducing more strong northwest flow enters into the study region. Besides, it is observed that the trough over the Bay of Bengal is stronger than that in light precipitation events. As a result, there is more moisture from the Arabian sea and the Bay of Bengal transported northward. From Fig. 7d, it is shown the body of the SAH is similar to that in Fig. 7b, while the SAH splits into two parts with the both GPH centers value exceeding $12540 \mathrm{gpm}$, with one relatively strong center lies over the Iranian plateau, and the other relatively weak center lies over the TP. The westerly jet stream over the Eurasia also keeps east- and west-branch, while the intensity of east branch westerly jet is weaker. In this situation, the QB is located at the southern flank of entrance zone of east branch of westerly jet stream and northern flank of the SAH, which still causes an appropriate dynamic condition for the precipitation in the QB. Fang et al. (2016) suggested the plateau monsoon can affect the moisture transport and large-scale circulation, which affects precipitation in Northwest China in turn. From Fig. 7a and Fig. 7c, we also find the plateau monsoon is important during the precipitation process, i.e., the greater the plateau monsoon, the stronger the precipitation in the QB (Fig. 7e).

\subsection{Quantitative analysis of major atmospheric circulation system}

Based on above results, it is shown that plateau monsoon, SAH, westerly jet and the anomalous low pressure over the QB, are very important for the precipitation in the QB. Besides, Chen et al. (2012) pointed out the moisture transported to the TP also depends on the Indian summer monsoon. To better quantitatively analyze the impact of these circulation systems on the precipitation in the $\mathrm{QB}$, corresponding indices are used to 
measure the change of their intensity based on definition methods described in the section of 2.2.4. As shown in Fig.8a, the value of DPMI is $-4.66,-4.81$ and -4.97 , and the value of WYI is $-5.64,-0.09$ and 0.41 for summer climate state, light and extreme precipitation events, respectively. It can be concluded that the plateau monsoon and South Asian summer monsoon become stronger when precipitation appears in the QB. The enhanced south Asian monsoon can bring more southerly flow northward, which originate from the Arabian Sea, the Bay of Bengal even the Eurasia carried by southern branch of westerlies (Fig. 3), then together with the strengthened plateau monsoon, to result in more precipitated moisture in the QB. Zhang et al. (2019) pointed out moisture sources from the areas dominated by the Asian monsoons, including the region ranging from the TP to the Indian Ocean and Indochina, have contributed more precipitated moisture for the northern TP. Therefore, it is no doubt that the South Asian summer monsoon and plateau monsoon are the contributors which make the stronger precipitated moisture entering the QB from low latitude and the Eurasia.

For summer climate state, light and extreme precipitation events, the value of SAHI is -1.41 , and are $-0.48,2.69$, respectively, indicating the overall intensity of the SAH is strongest during the period of extreme precipitation. For extreme precipitation events, although the center of the SAH is divided into two parts and the maximum value of the center of SAH is 12540 gpm (Fig. 7d), the intensity of the SAH is stronger compared with that in light precipitation. The value of LSPI is $2.75,2.37$ and 3.35 for summer climate state, light precipitation events and extreme precipitation events, respectively, which denotes there is usually a cyclonic circulation exits in the QB, consistent with results in Fig.6. The value of LSPI of light precipitation events is very similar to the climate state, with an insignificantly weaker intensity, indicating that strong LSPI is not the necessary factor for light precipitation in the QB. But for the extreme precipitation 
events, strong LSPI is needed, revealing this cyclonic circulation is facilitating to the precipitation in the northeastern QB. The value of WJI is $1.66,1.89$ and 0.48 for summer climate state and two types events, respectively, indicating the westerly jet weakens when extreme precipitation occurs. However, from the Fig. $7 b(d)$, it is shown the westerly jet splits into east- and west-branch during the period of precipitation especially extreme precipitation in the QB, indicating that the westerly jet can affect precipitation in the QB by its pattern instead of its intensity.

The structure of east- and west-branch of the westerly jet is the most prominent in precipitation events especially extreme precipitation events. And the center of the SAH divides into two parts during the period of extreme precipitation (Fig.7b(d)). In fig. 7e$\mathrm{f}$, there are positive and negative GPH anomalies ranging from the Iranian plateau to the Baikal Sea and the east of Mediterranean to the eastern Europe plateau, respectively. The difference of the SAH, westerly jet and GPH indicate the meridional circulation of extreme precipitation events is more obvious than that of light precipitation events. As a result, to simply analysis the intensity of meridional (zonal) circulation, the WCI was computed and normalized. Here, a large and positive value indicates that the westerly wind is strong, corresponding to the zonal circulation, while a negative and large absolute value indicates that the westerly wind is weak, corresponding to the meridional circulation.

As shown in Fig. 8b, the values of WCI show a pattern as extreme precipitation events $>$ light precipitation events $>$ summer climate state between $30^{\circ} \mathrm{E}$ and $75^{\circ} \mathrm{E}$. The WCI are below zero for summer climate state and light precipitation events, while is above zero from $50^{\circ} \mathrm{E}$ to $60^{\circ} \mathrm{E}$ and is below zeros from $35^{\circ} \mathrm{E}$ to $50^{\circ} \mathrm{E}$, and from $60^{\circ} \mathrm{E}$ to $75^{\circ} \mathrm{E}$ for extreme precipitation events. Also, the WCI show another pattern as summer climate state>light precipitation events>extreme precipitation events, and is 
below zero from $79^{\circ} \mathrm{E}$ to $110^{\circ} \mathrm{E}$ (presented in green box). Therefore, the meridional change of the values of $\mathrm{WCI}$ indicates that the zonal circulation from $30^{\circ} \mathrm{E}$ to $75^{\circ} \mathrm{E}$ and the meridional circulation from $79^{\circ} \mathrm{E}$ to $110^{\circ} \mathrm{E}$ of extreme precipitation events are the strongest compared with summer climate state and light precipitation events. The strong zonal circulation over the Europe leads to more moisture eastward. Then the strong meridional circulation lying the QB and its upstream region makes this eastward moisture into the QB by the northern and southern branch of the westerlies. This may be the reason why the moisture transport across the western and southern boundaries increases significantly when precipitation especially extreme precipitation occurs in the QB (shown as in Fig. 5). Based on the above analysis, it can be concluded that the moisture from Eurasia is also vital important for the precipitation in the QB. Such result is consistent with study of Sun et al. (2014), who analyzed the moisture source of the eastern TP, and found the moisture released in the eastern TP was substantially from the Eurasian continent in both summer and winter.

In general, large-scale circulation can provide a favorable background for the precipitation and associated with moisture transport in a region. Fang et al. (2016) revealed that the SAH strengthens and shifts northward during the period of strong plateau monsoon. Meantime, the westerlies jumps northward earlier than normal year and the trough in the west of Lake Baikal deepens, which facilitates to the precipitation in northwest China. Due to the local characteristics of precipitation in the QB, the atmospheric circulation during precipitation here is not completely consistent with that of the northwest China. Through the analysis of sections 4.1 and 4.2, we find the SAH enhances and the westerlies jet splits into west- and east-branch during the period of precipitation in the QB. Meantime, the plateau monsoon and South Asian summer monsoon strength. Additionally, the deepened trough in the northwest of the QB and 
the enhanced meridional circulation are also conducive to the occurrence of extreme precipitation in the study region.

\section{Relationship between precipitation and atmospheric heat source}

\subsection{The heat source pattern}

The diabatic heating over the TP plays an important role in the atmospheric circulation over the TP and its adjacent areas (Zhao and Chen, 2001), as well as the precipitation in China (Xu et al., 2013). The QB is located at the northeastern TP, are there any relationship between summer precipitation here and the heat source? This issue is discussed in this section.

Fig. 9 shows the spatial distribution of apparent heat source $\left(<Q_{1}>\right)$ and apparent moisture sink $\left(<Q_{2}>\right)$ for summer climate state, $<Q_{1}>,<Q_{2}>$ and their anomalies for two types of events. The atmospheric apparent heat source is mainly concentrated over the TP and its surrounding areas, with the maximum of $\left\langle\mathrm{Q}_{1}\right\rangle$ located at the south slope of the TP, the east coast of the Bay of Bengal and the Arabian Sea. The $\left\langle\mathrm{Q}_{1}>\right.$ over the $\mathrm{QB}$ increases gradually from the northern $\mathrm{QB}$ to the southern $\mathrm{QB}$, its values and this anomalous values for extreme precipitation events are larger than that of both summer climate state and light precipitation events. The pattern of $\left\langle\mathrm{Q}_{2}>\right.$ is similar to that of the $\left\langle\mathrm{Q}_{1}>\right.$. For the $\mathrm{QB}$, the values of $<\mathrm{Q}_{2}>$ and its anomaly are positive in the central-eastern $\mathrm{QB}$, while are negative in the western $\mathrm{QB}$, indicating there are moisture sink in the central-eastern QB and the moisture source in the western QB that may be responsible to the precipitation in the eastern QB. Besides, as consistent with the moisture flux anomaly, the positive values of $\left\langle\mathrm{Q}_{2}>\right.$ increase with the enhanced precipitation which can be seen from Fig. 9d and Fig. 9f.

It also can be seen that the changes of $\left\langle\mathrm{Q}_{1}>\right.$ and $<\mathrm{Q}_{2}>$ over the QB are more obvious than that of the whole $\mathrm{TP}$, suggesting the pressure-meridional cross section of 
apparent heat source $\left(Q_{1}\right)$ and apparent moisture sink $\left(Q_{2}\right)$ and their anomalies averaged between $35^{\circ} \mathrm{N}$ and $40^{\circ} \mathrm{N}$, as shown in Fig. 10. It can be seen that the apparent heat source and apparent moisture sink extends from surface to the tropopause and are more remarkable near the surface than that on other layers, especially in the eastern QB. Another evident fact is that the intensity of $\left\langle Q_{1}\right\rangle$ and $\left\langle Q_{2}\right\rangle$ during extreme precipitation is larger than that in summer climate state and light precipitation events from $90^{\circ} \mathrm{E}$ to $100^{\circ} \mathrm{E}$. How does the diabatic heat affect the weather and climate over the east Asia? Some scholars have performed research about this problem. The heat source over the TP has an impact on the Asian summer monsoonal circulation and the formation of the south Asian high (Xu et al., 2013; Wu et al., 2012; Duan et al., 2005). Furthermore, the deep convection is closely related with $\left\langle\mathrm{Q}_{1}>\right.$ and $\left\langle\mathrm{Q}_{2}>\right.$ over

the eastern TP. Greater $<\mathrm{Q}_{1}>$ and $<\mathrm{Q}_{2}>$, stronger upward motion presented over the eastern TP (Chen et al., 2015). It is evident that the heat source over the TP affects the atmospheric circulation associate with the local vertical motion and the moisture source. So, the strengthened atmospheric heat source over the QB may be closely related to the summer precipitation especially extreme precipitation here, which will be discussed in the next section.

\subsection{Relationship between moisture transport and the apparent heat source}

To have a complete description of the processes of atmospheric heating affects precipitation, it is also necessary to know the relationship between the moisture transport and heat source over the QB. Besides, in order to highlight the effect of the local heat source, we calculated the cross correlation between the apparent heat source $\left(<\mathrm{Q}_{1}>\right)$ over the QB and the whole column moisture flux of two types events (Fig. 11). Because $<Q_{1}>$ includes $<Q_{2}>$, radiative heating and heat sink due to vertical 
transport of dry-static energy and latent heat (Yanai and Tomita, 1998), we concentrate only on the effect of apparent heat source $\left(<Q_{1}>\right)$ on the moisture transport here.

For the light precipitation events, there is only the southward correlation vectors in light-blue region in the north of QB on lag -1 day (Fig. 11a). While there are the southward correlation vectors in the light-blue regions in the south of Aral Sea, the northern Indian subcontinent and the northwest of the QB, and there are the northward correlation vectors in the light-red region in the eastern TP on lag 0 day (Fig. 11c). For the extreme precipitation events, on lag -1 day, there are the northward correlation vectors in light-red regions ranging from the east coast of the Bay of Bengal to the eastern TP, and the southward correlation vectors in light-blue region over the southern Indian subcontinent which contribute a lot to this northward correlation vectors (Fig. 11b). And there are only northward correlation vectors in light-red region over the eastern TP on lag 0 day.

The above across correlation analysis indicates that the $<\mathrm{Q}_{1}>$ over the QB can affect the moisture transport. The convergence correlation vectors in the TP and its adjacent areas of light precipitation events represent that the moisture flux is "pumped up" by the heat source over the QB (Fig. 11c). This convergence flow denotes that there is a clear cyclonic wind field over the TP, indicating the apparent heat source over the QB can drive an abnormal cyclone circulation. This result is consistent with the thermal effect of the entire TP (Zhao and Chen, 2001). As a result, it is clear the apparent heat source over the QB mainly affects the synchronous moisture transport around the TP and its surrounding areas for light precipitation events. For the extreme precipitation, the southward vectors over the southern Indian subcontinent turns northeastward in the southern the Bay of Bengal, and then becomes the southerly moisture flux which ranges from the east coast of the Bay of Bengal to the eastern TP. It can be concluded that the 
early-stage apparent heat source over the QB can affect the moisture transport from the east part region of the South Asian summer monsoon region to the eastern TP which is controlled by the thermal of the TP (Wu et al., 2012), while the synchronous heat source only affects the moisture transport in the eastern TP. Additionally, there is also an abnormal cyclone circulation over the TP on lag 0 day stimulated by heat source which facilitates the convergence of moisture and upward motion over the QB.

\subsection{Relationship between convective activity and the apparent heat source}

The above analysis reveals that the apparent heat source over the QB can trigger an abnormal cyclonic circulation over the TP on lag 0 day for both light and extreme precipitation events, and this abnormal cyclone can affect the vertical motion over the QB. Thereby, we calculated the correlation relationship between apparent heat source $\left(<\mathrm{Q}_{1}>\right)$ and $\omega$ in order to further investigate the effect of diabatic heat over the QB on convective motion (Fig .12).

As is shown in Fig .12, there is negative correlation between $\left\langle Q_{1}\right\rangle$ and $\omega$ over the QB passing the $90 \%$ significant level for two types events, which indicates the larger atmospheric apparent heat source is corresponding to stronger the upward motion in the QB. Hence, the abnormal cyclonic circulation over the TP stimulated by the apparent heat source contributes to the upward motion over the QB. The absolute value of negative correlation coefficient of light precipitation events is larger than that of extreme precipitation events, indicating the source heat over the QB has a stronger impact on convective activity for the light precipitation. In conclusion, the heat source over the QB can not only affect the moisture transport but also the upward motion in the QB, which influences further the pattern of precipitation in the QB.

\section{Summary and discussion}


This study analyzes the characteristics and formation causes for light and extreme precipitation in boreal summer in the QB, which located over the northeast TP and shows regional features in weather and climate. In the $\mathrm{QB}$, the extreme (light) precipitation thresholds in the eastern region are greater than that in the western region, which is highly consistent with distribution of total rainfall frequency and magnitude. The thresholds of light precipitation events for most regions are less than $2 \mathrm{~mm}$. The maximum of extreme precipitation thresholds is over $16 \mathrm{~mm}$ in De Lingha station and Du Lan station, and the minimum of the thresholds is less than $6 \mathrm{~mm}$ in the centralwestern Basin. Besides, although as a small probability event, extreme precipitation contributes a lot to the total summer precipitation in the QB.

There are two main transport channels for moisture in the OB. One is the north branch moisture channel, with the moisture transporting along which is mainly from the Eurasia and carried by the westerlies, contributing around $48.2 \%$ and $55.8 \%$ of moisture for light and extreme precipitation events, respectively. The other is the south branch moisture channel, with moisture originating from the Arabian Sea and the Bay of Bengal, and then transported by the joint role of the South Asian summer monsoon and the plateau monsoon toward the $\mathrm{QB}$, which provides $51.8 \%$ and $44.2 \%$ of moisture for light and extreme precipitation events, respectively. Moisture transport across boundaries of the QB is characterized the summer precipitation over the QB is largely attributed to the increased moisture transport across the western and southern boundaries, especially for the extreme precipitation. The decreased moisture output from the eastern boundary is additionally responsible for the increased extreme precipitation. In specific, compared with the summer climatological state, the moisture transport increases by $14.45 \mathrm{~kg} . \mathrm{s}^{-1}$ for light precipitation events and by $27.37 \mathrm{~kg} . \mathrm{s}^{-1}$ for extreme precipitation events from the western boundary, and increases by $21.97 \mathrm{~kg} . \mathrm{s}^{-1}$ 
for light precipitation events and by $44.31 \mathrm{~kg} . \mathrm{s}^{-1}$ for extreme precipitation events from the southern boundary. The moisture output across the eastern boundary increases by $17.81 \mathrm{~kg} . \mathrm{s}^{-1}$ for light precipitation events and decreased by $53.91 \mathrm{~kg} \cdot \mathrm{s}^{-1}$ for extreme precipitation events. The convective activity during precipitation over the $\mathrm{QB}$ is significant because there are the upward motion and horizontal wind convergence below $550 \mathrm{hPa}$ and horizontal wind divergence above 550hPa. Especially, the intensity of convective activity is stronger for the extreme precipitation compared with that during light precipitation.

The light (extreme) precipitation in the QB is associated with the weak ridge over the Caspian Sea and Aral Sea at mid-high latitudes, which drives more westerly moisture and cold air from the Eurasia into the basin. In addition, the enhanced South Asian summer monsoon and plateau monsoon bring more moisture originating from Arabian Sea and the Bay of Bengal even the Eurasia, resulting in more moisture release to the QB. Finally, the strengthened meridional circulation may be responsible to the increase of precipitation in the QB. The meridional circulation enhances, the westerly jet stream splits into east- and west-branch, and the SAH strengthens, causing a divergence environment in the upper level over the QB. While, for the extreme precipitation events, the trough is obvious in the northwest of the QB, the east- and west-branch structure of westerly jet is more significant, and the center of SAH divides into two parts with the main center located over the Iranian plateau.

The apparent heat source is another important factor influencing the formation of precipitation events, by both affecting the moisture transport and reinforcing the local convective activity. For light precipitation events, the apparent heat source over the QB mainly affects the synchronous moisture transport which is from the south of Aral Sea, the north of Indian subcontinent, the northwest of the QB, and the eastern TP. While, 
for extreme precipitation events, the apparent heat source ahead of one day affects the moisture transport originating from the east part region of the South Asian summer monsoon and the southern of Indian subcontinent.

In this study, we have studied the impact of the apparent heat source over the QB which indicates the total atmospheric diabatic heat on the moisture transport and convective activity associated with precipitation, while the contribution of different component of the atmospheric heat source is unclear. Especially, previous studies ( $\mathrm{Wu}$ et al., 2007) revealed that the sensible heat over the TP affects the Asian summer monsoon and the precipitation in the Asian. As a part of the TP, the QB is whether influenced by the local sensible heat or not, should be studied further. As an inland basin, the topography of the QB and its surrounding areas are very complex, such as the TP, the Qilian Mountain, the Kunlun Mountains, and the Altun Mountains. The effects of the topography on the local weather and climate, as well as the role of meso and small-scale weather systems, are planned to study further by using numerical model experiment.

Acknowledgement: This work was supported by the National Key research \& development (R\&D) Program of China (Grant/Award Number: 2019YFA0606801; SQ2018YFC040178) and the Natural Science Foundation of China (41775051).

\section{References:}

1. Allan, R. P., \& Soden, B. J. (2008). Atmospheric warming and the amplification of precipitation extremes. Science, 321(5895), 1481-1484.

2. Bo, S., Yali, Z., \& Wang, H. (2011). The recent interdecadal and interannual variation of water vapor transport over eastern China. Advances in Atmospheric Sciences, 28(5), 1039.

3. Chen B., Xu X. D., Yang, S., \& Wei, Z. (2012). On the origin and destination of atmospheric moisture and air mass over the TP. Theoretical \& Applied Climatology, 110(3), 423-435.

4. Chen, J., Wu, X., Yin, Y., \& Xiao, H. (2015). Characteristics of Heat Sources and Clouds over Eastern China and the Tibetan Plateau in Boreal Summer. Journal of Climate, 28, 7279-7296. 
5. Cuo, L., Zhang, Y., Wang, Q., Zhang, L., Zhou, B., Hao, Z., \& Su, F. (2013). Climate change on the northern TP during 1957-2009: Spatial patterns and possible mechanisms. Journal of Climate, 26, 85-109.

6. Duan A. M., \& Wu G. X. (2005). Role of the Tibetan Plateau thermal forcing in the summer climate patterns over subtropical Asia. Climate Dynamics, 24(7/8), 793-807.

7. Fang, Y., Fan, G., Lai, X., Hua, W., \& Zhang, Y. (2016). Relations between intensity of the Qinghai-Xizang Plateau Monsoon and Movement of the Northern Hemisphere Westerlies. Plateau Meteorology, 35(06), 1419-1429 (in Chinese).

8. Feng, L. \& Zhou, T. (2012). Water vapor transport for summer precipitation over the TP: Multidata set analysis. Journal of Geophysical Research: Atmospheres, 117(D20), 20114.

9. Feng, S., Saralees, N., \& Qi, H. (2007). Modeling Annual Extreme Precipitation in China Using the Generalized Extreme Value Distribution. Journal of the Meteorological Society of Japan. Ser. II, 85, 599-613.

10. Fu, G., Yu, J., Yu, X., Ouyang R., \& Min, L. (2013). Temporal variation of extreme rainfall events in China, 1961-2009. Journal of Hydrology, 487, 48-59.

11. Gao, Y., Li, X., Leung, L. R., Chen, D., \& Xu, J. (2015). Aridity changes in the TP in a warming climate. Environmental Research Letters, 10(3), 34013-34013.

12. Hsu, P., Lee, J., \& Ha, K. (2016). Influence of boreal summer intraseasonal oscillation on rainfall extremes in southern China. International Journal of Climatology, 36.

13. Huang, W., Feng, S., Chen, J., \& Chen, F. (2015). Physical Mechanisms of Summer Precipitation Variations in the Tarim Basin in Northwestern China. Journal of Climate, 28, 3579-3591.

14. Huang, Y., Ren, · H., Chadwick, • R. \& Deng, Y. • (2021). Decomposition of • projected summer rainfall change over East Asia based on timeslice experiments. Climate Dynamics, 56, 2531-2549.

15. Jiang, Z., Shen, Y., Ma, T., Zhai, P., \& Fang, S. (2014). Changes of precipitation intensity spectra in different regions of mainland China during 1961-2006. Journal of Meteorological Research, 28, 1085-1098.

16. Li, B., Ding, R., Qin, J., Zhou, L., Hu, S., \& Li, J. (2019) Interdecadal changes in potential predictability of the summer monsoon in East Asia and South Asia. Atmos Sci Lett., e890.

17. Li C., Deng Y., Cui C., Wang X., Dong X. \& Jiang X. (2020). Hydrometeor budget of the Meiyu frontal rainstorms associated with two different atmospheric circulation patterns. Journal of Geophysical Research: Atmospheres, 125.

18. Ma, S., Zhou, T., Dai, A., \& Han, Z. (2015). Observed Changes in the Distributions of Daily Precipitation Frequency and Amount over China from 1960 to 2013. Journal of Climate, 28, 6960-6978.

19. Rossby C. (1939). Relation between Variations in the Intensity of the Zonal Circulation of the Atmosphere and the Displacements of the Semi-permanent Centers of Action. Journal of Marine Research, 2(1), 38-55.

20. Shen J., Zhang C., Liu J., \& Ma, Y. (2016). Temperature Variation Characteristics in Qaidam Basin in Recent 35 Years. Chinese Agricultural Science Bulletin, 32(34), 159-165 (in Chinses).

21. Shiu, C., Liu, S. C., Fu, C., Dai, A., \& Sun, Y. (2012). How much do precipitation extremes change in a warming climate? Geophysical Research Letters, 39(17), 17707. 
22. Stein, A. F., Draxler, R. R., Rolph, G. D., Stunder, B., Cohen, M. D., \& F, Ngan. (2016). NOAA's HYSPLIT atmospheric transport and dispersion modeling system. Bulletin of the American Meteorological Society, 150504130527006.

23. Sun, B., \& Wang, H. (2014). Moisture sources of semiarid grassland in China using the Lagrangian particle model flex part. Journal of Climate, 27(6), 2457-2474.

24. Trenberth, K. E., Dai, A., Rasmussen, R. M., \& Parsons, D. B. (2003). The Changing Character of Precipitation. Bulletin of the American Meteorological Society, 84, 1205-1218.

25. Trenberth, K.E. (1999). Conceptual Framework for Changes of Extremes of the Hydrological Cycle with Climate Change. Climatic Change, 42, 327-339.

26. Webster, P. J., \& Yang, S. (1992). Monsoon and Enso: Selectively Interactive Systems. Quarterly Journal of the Royal Meteorological Society, 118(507), 877926.

27. Wei, W., Zhang, R., Wen, M., \& Yang, S. (2017). Relationship between the Asian Westerly Jet Stream and Summer Rainfall over Central Asia and North China: Roles of the Indian Monsoon and the SAH. Journal of Climate, 30(2), 537-552.

28. Wei, W., Zhang, R., Wen, M., Kim, B. J., \& Nam, J. C. (2015). Interannual variation of the south Asian high and its relation with Indian and east Asian summer monsoon rainfall. Journal of Climate, 28(7), 2623-2634.

29. Wei, W., Zhang, R., Wen, M., Rong, X., \& Li, T. (2014). Impact of Indian summer monsoon on the SAH and its influence on summer rainfall over China. Climate Dynamics, 43(5-6), 1257-1269.

30. Wen, G., Huang, G., Tao, W., \& Liu, C. (2016). Observed trends in light precipitation events over global land during 1961-2010. Theoretical \& Applied Climatology, 125, 161-173.

31. Wu, G., Li, W., \& Guo, H. (1997). Sensible heat pump over the Qinghai-Xizang (Tibetan) Plateau and Asian summer monsoon $[\mathrm{M}] / /$ Ye Duzheng. Collected Works for the Commemoration of Professor Zhao Jiuzhang. Beijing: Science Press, 116126 (in Chinese).

32. Wu, G., Liu, Y., He, B., Bao, Q., Duan, A., \& Jin, F. F. (2012). Thermal Controls on the Asian Summer Monsoon. Scientific Reports, 2, 404.

33. Wu, G., Liu, Y., Zhang, Q., Duan, A., Wang, T., Wan, R., Liu, X., Li, W., Wang, Z., \& Liang, X. (2007). The Influence of Mechanical and Thermal Forcing by the Tibetan Plateau on Asian Climate. Journal of Hydrometeorology, 8, 770-789.

34. Wu, J., Gao, X., Giorgi, F., Chen, Z., \& Yu, D. (2012). Climate effects of the Three Gorges Reservoir as simulated by a high resolution double nested regional climate model. Quaternary International, 282, 27-36.

35. Xu, X., Lu, C., Ding, Y., Shi, X., Guo, Y., \& Zhu, W. (2013). What is the relationship between China summer precipitation and the change of apparent heat source over the Tibetan Plateau? Atmospheric Science Letters, 14.

36. Yanai, M., \& Tomita, T. (1998). Seasonal and Interannual Variability of Atmospheric Heat Sources and Moisture Sinks as Determined from NCEP-NCAR Reanalysis. Journal of Climate, 11(3), 463-482.

37. Yanai, M., Esbensen, S., \& Chu, J. H. (1973). Determination of bulk properties of tropical cloud clusters from large-scale heat and moisture budgets. Journal of Atmospheric Sciences, 30(4), 611-627.

38. Yao, T., Masson-Delmotte, V., Jing, G., Yu, W., Yang, X., Risi, C., Sturm, C., Werner, M., Zhao, H., He, Y., Ren, W., Tian, L., Shi, C. \& Hou, S. (2013). A review of climatic controls on $\delta$ O-18 in precipitation over the Tibetan plateau: observations and simulations. Reviews of Geophysics, 51, 525-548. 
39. Ye, D., Luo, S., \& Zhu, B. (1957). The flow structure and tropospheric heat balance over Tibetan Plateau and its surrounding. Acta Meteorologica Sinica, 28, 108-121 (in Chinese)

40. You, Q., Kang, S., Aguilar, E., \& Yan, Y. (2008). Changes in daily climate extremes in the eastern and central TP during 1961-2005. Journal of Geophysical Research, 113.

41. Yu, L., Yang, Q., Timo, V., Svetlana, J., Liu, J., Sun, Q., \& Li, Y. (2018). Features of Extreme Precipitation at Progress Station, Antarctica. Journal of Climate, 31, 9087-9105.

42. Zhai, P., \& Pan, X. (2003). Change in Extreme Temperature and Precipitation over Northern China During the Second Half of the 20th Century. Acta Geographica Sinica, 58, 1-10.

43. Zhai, P., Zhang, X., Hui, W., \& Pan, X. (2005). Trends in Total Precipitation and Frequency of Daily Precipitation Extremes over China. Journal of Climate, 18(7), 1096-1108.

44. Zhang, C., Tang, Q., \& Chen, D. (2017). Recent changes in the moisture source of precipitation over the TP. Journal of Climate, 30, 1807-1819.

45. Zhang, C., Tang, Q., Chen, D., van der Ent, R. J., Liu, X., Li, W., \& Haile, G. G. (2019). Moisture Source Changes Contributed to Different Precipitation Changes over the Northern and Southern TP. Journal of Hydrometeorology, 20, 217-229.

46. Zhang, P., Liu, Y., \& He, B. (2016). Impact of East Asian Summer Monsoon Heating on the Interannual Variation of the SAH. Journal of Climate, 29, 159-173.

47. Zhang, W., Cui, X., Huang, R., \& Li, H. (2019). An Investigation of the Characteristics and Mechanism of the High Precipitation Supercell in the Beijing "623" Severe Rainstorm. Chinese Journal of Atmospheric Sciences, 43, 1171-1190 (in Chinese).

48. Zhao, P., \& Chen L. (2001). Interannual variability of atmospheric heat source/sink over the Qinghai-Xizang (Tibetan) Plateau and its relation to circulation. Advances in Atmospheric Sciences, 18(1), 106-116.

49. Zhou, J., Wen, J., Wang, X., Jia, D., \& Chen, J. (2016). Analysis of the QinghaiXizang Plateau Monsoon Evolution and Its Linkages with Soil Moisture. Remote Sensing, 8(6), 493.

50. Zhou, T., Song, F., Lin, R., Chen, X., \& Chen, X. (2013). The 2012 North China floods: Explaining an extreme rainfall event in the context of a longer-term drying tendency. Bulletin of the American Meteorological Society, 94, S49-S51.

51. Zhou, Y., Fan, G., Hua, W., Wang, B., Zhu, L., \& Zhou, D. (2015). Distribution Characteristics of Plateau Monsoon and a Contrastive Analysis of Plateau Monsoon Index. Plateau Meteorology, 34(06), 1517-1530 (in Chinese). 


\section{Differences in the causes of light and extreme precipitation for the Qaidam Basin in summer}
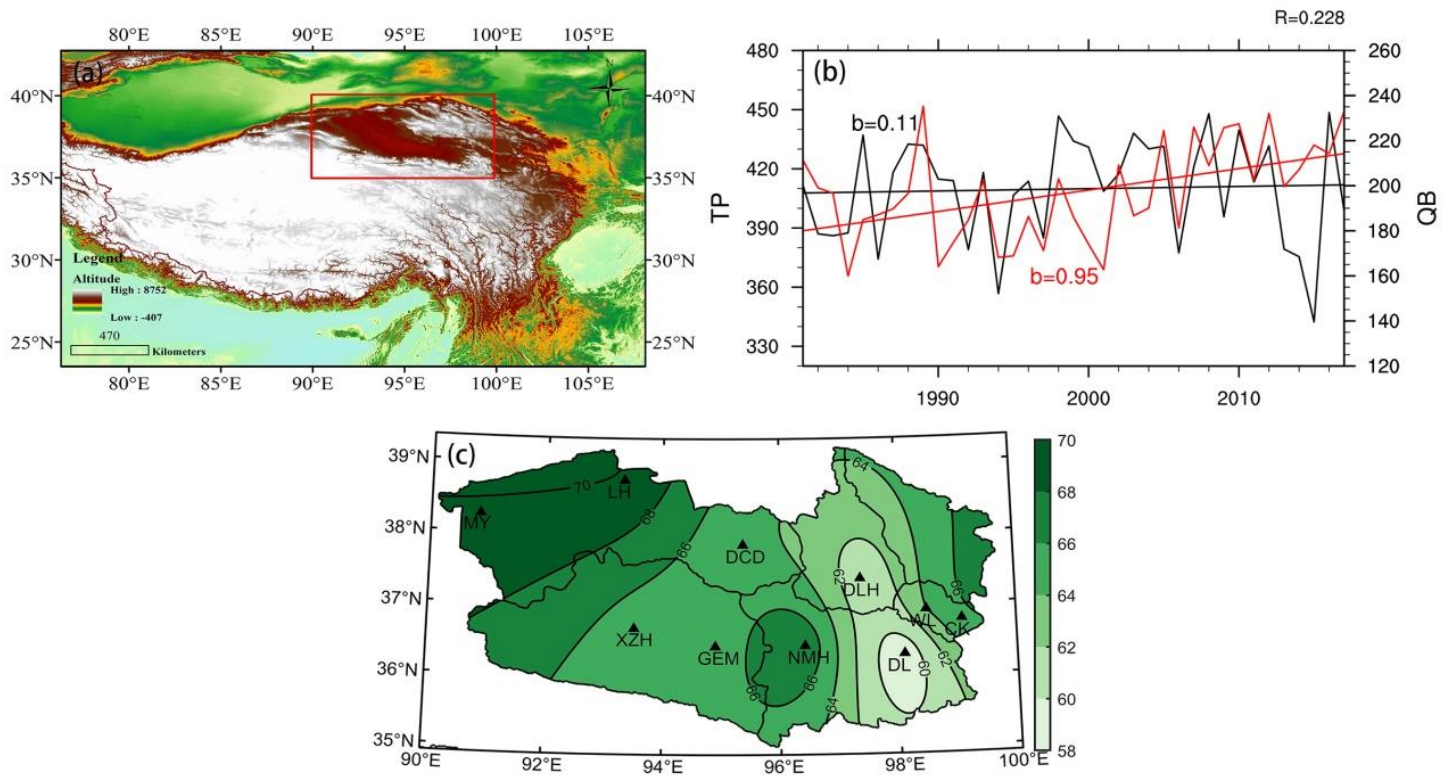

Fig.1 (a) The topographic of $\mathrm{QB}$, red box indicates the $\mathrm{QB}$, (b) The time series of annual precipitation in the QB (Averaged over $35^{\circ} \mathrm{N} \sim 40^{\circ} \mathrm{N}$, over $90^{\circ} \mathrm{E} \sim 100^{\circ} \mathrm{E}$, red curve) and the TP (Averaged over the red polygon showed in Fig.9, black curve) during 1981-2017,respectively (units: mm), the red (black) straight line represents the linear trend of annual precipitation in the QB (TP), and $b$ represents the slope of the best fit line,(c) The percentage of summer precipitation to annual precipitation in the QB (units:100\%) 

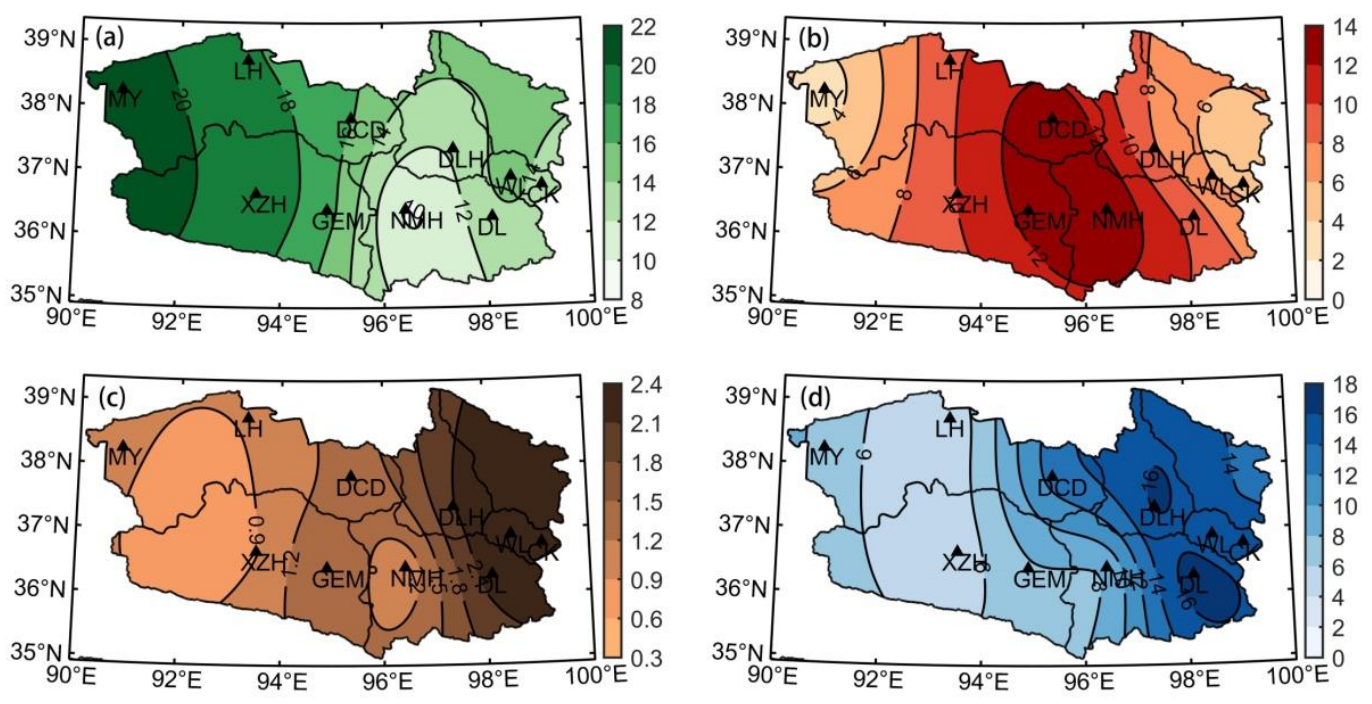

Fig.2 The spatial distribution of the percentage of (a) total light precipitation to summer precipitation, and

(b) total extreme precipitation to summer precipitation (units:100\%), the spatial distribution of (c) the light precipitation thresholds and (d) the extreme precipitation thresholds (units: $\mathrm{mm}$ ) 

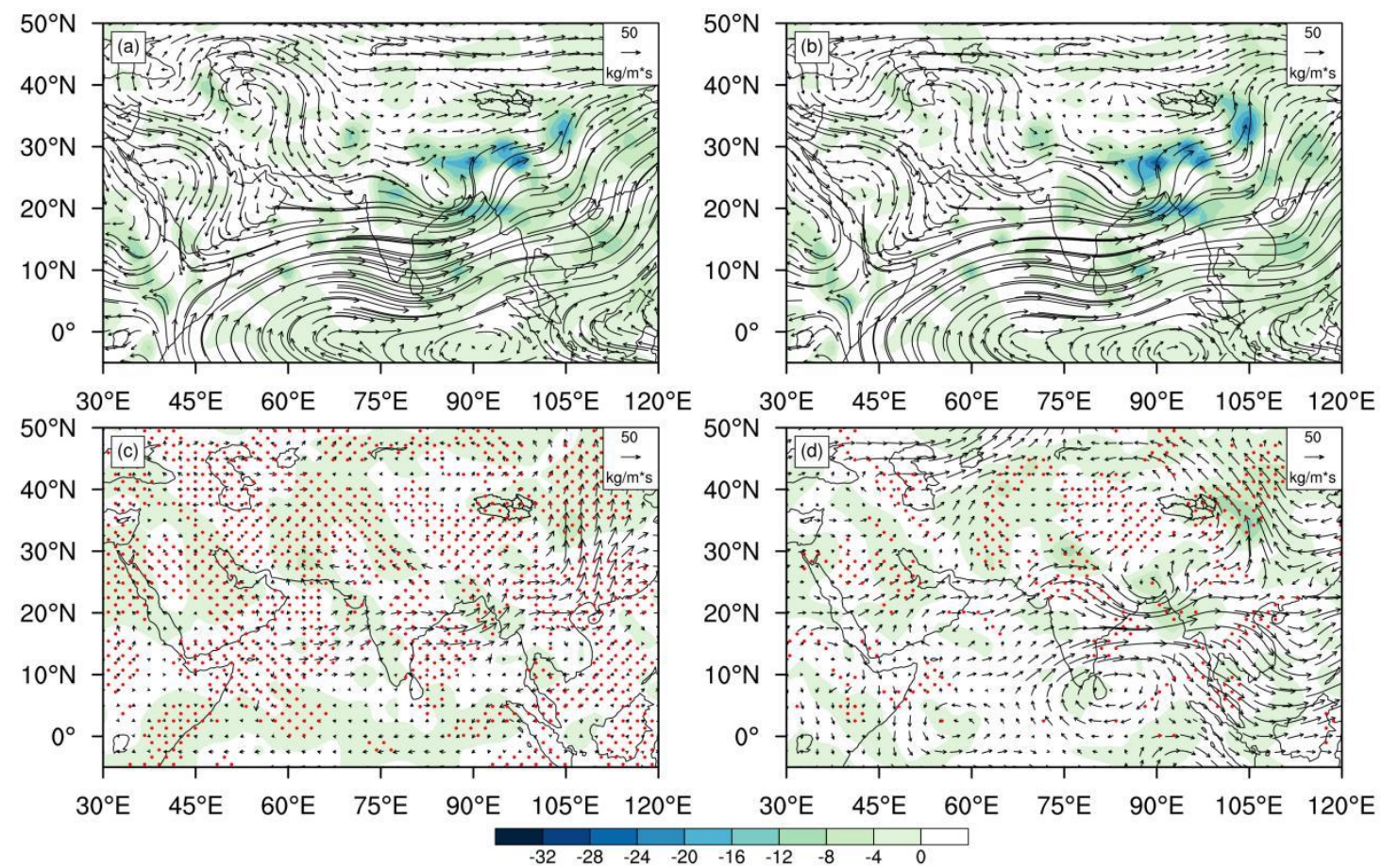

Fig. 3 Composite of the vertically integrated of moisture flux (vectors, units: $\mathrm{kg}^{-\mathrm{m}^{-1}} \cdot \mathrm{s}^{-1}$ ) and moisture flux divergence (shaded, units: $10^{-5} \mathrm{~kg} \cdot \mathrm{m}^{-2} \cdot \mathrm{s}^{-1}$ ) of (a) the light precipitation events, and (b) the extreme precipitation events. The anomaly of vertically integrated of moisture flux (vectors, units:kg. $\mathrm{m}^{-1} \cdot \mathrm{s}^{-1}$ ) and moisture flux divergence (shaded, units: $10^{-5} \mathrm{~kg} \cdot \mathrm{m}^{-2} \cdot \mathrm{s}^{-1}$ ) of (c) the light precipitation events, and (d) the extreme precipitation events, the dotted areas indicate pass the $90 \%$ significance level, the black boundary around $35^{\circ} \mathrm{N}-40^{\circ} \mathrm{N}, 90^{\circ} \mathrm{E}-100^{\circ} \mathrm{E}$ indicates the outline of the $\mathrm{QB}$ (the same below) 


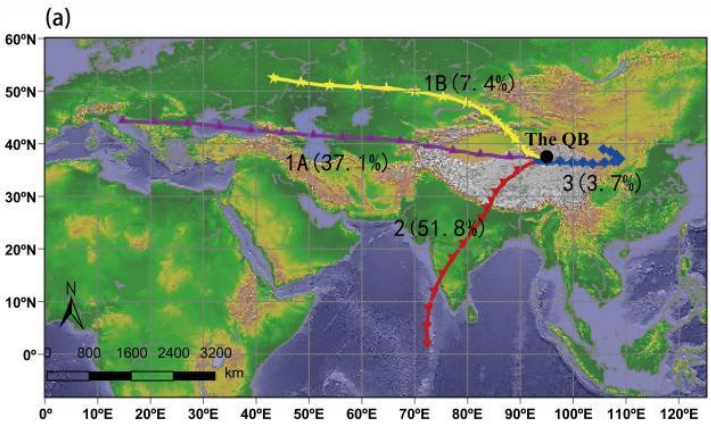

(c)

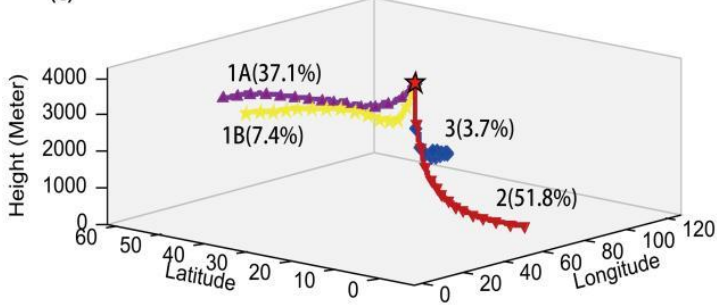

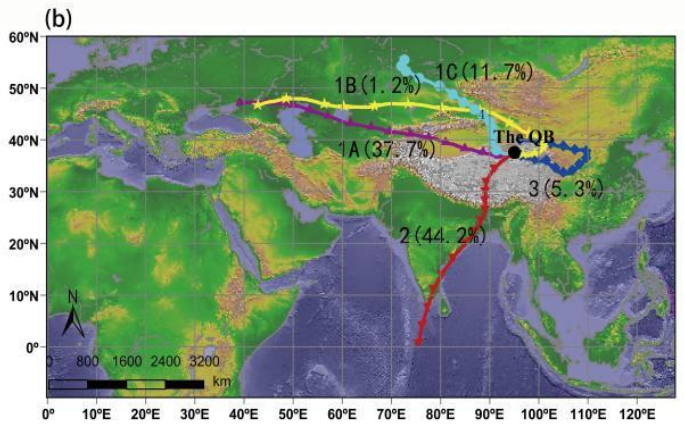

(d)

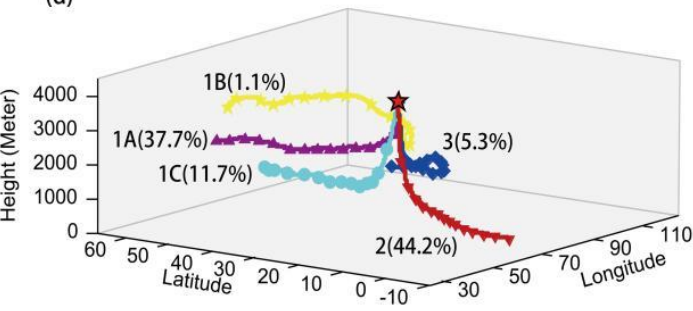

Fig.4 The spatial distribution of moisture channels of (a) the light precipitation events, and (b) the extreme precipitation events. The three-dimensional schematic diagram of the moisture channels of (c) the light precipitation events, and (d) the extreme precipitation events 
(a1)

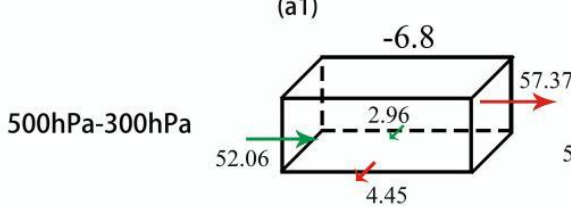

(a2) (b1)

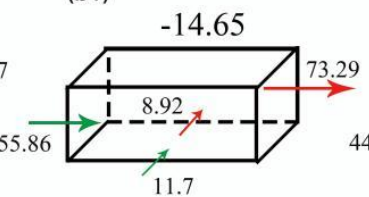

(b2)

$+14.48$

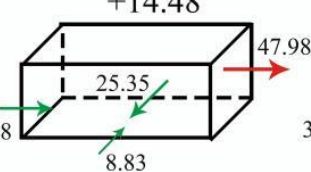

(b3)

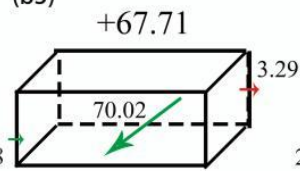

(c3)

(c1)

4.23

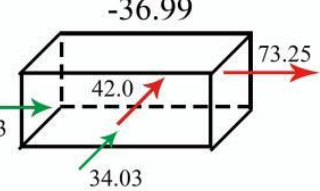

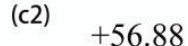

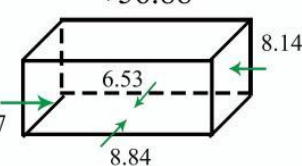

0.98

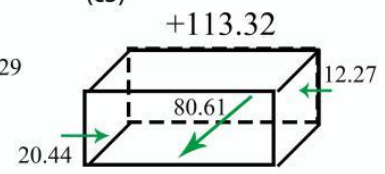

Ps-700hPa

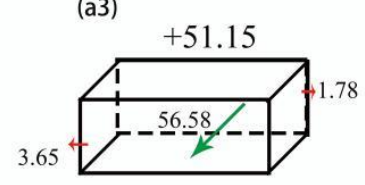

(b4)

(c4)

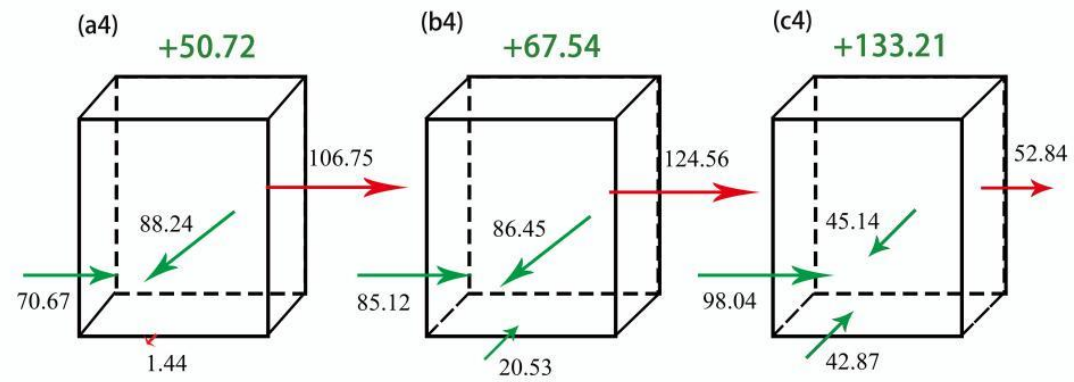

Fig.5 Vertical distribution of moisture transport in the three layers across the four boundaries of the QB (units:kg. $\mathrm{s}^{-1}$ ), (a1), (b1), and (c1) represent 500-300hPa, (a2), (b2), and (c2) represent 700-500hPa, (a3), (b3), and (c3) represent surface pressure to $700 \mathrm{hPa},(\mathrm{a} 4)$, (b4), and (c4) represent the whole air column. the left panel is summer climate state during 1981-2017, the middle panel is the light precipitation events, and the right panel is the extreme precipitation events. The green (red) arrows indicate the moisture influxes (outfluxes), the number in black above boxes indicate net moisture influx at upper (middle or low) layer, and the numbers in green above boxes indicate total net moisture influx in whole air column. 

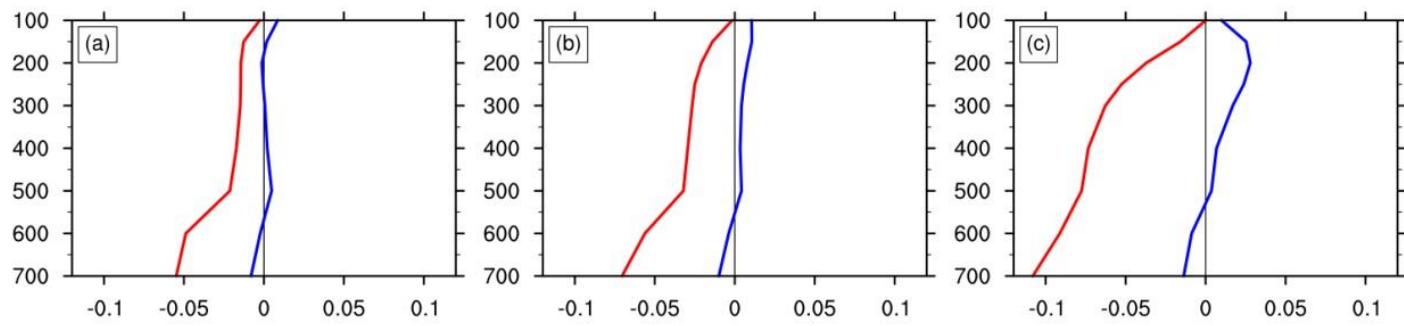

Fig.6 The vertical profile of $\omega$ (units: Pa.s ${ }^{-1}$, red line), and divergence of horizontal wind (units: $10^{-4} \cdot \mathrm{s}^{-1}$, blue line) in the QB, (a) summer climate state, (b) the light precipitation events, and (c) the extreme precipitation events. 

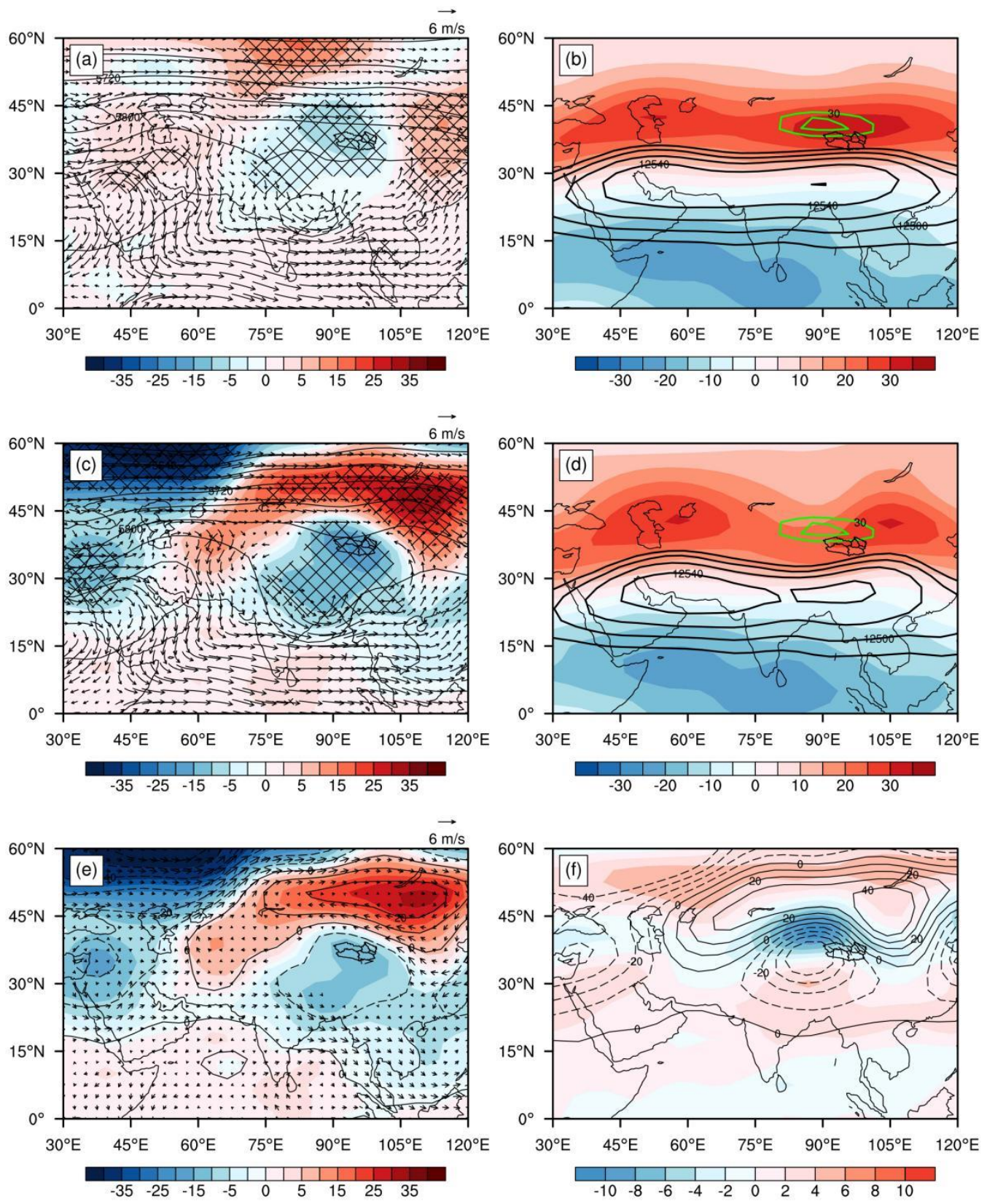

Fig.7 Composite of 500 hPa GPH (contour, units: gpm), its anomaly (shaded, units: gpm) and $700 \mathrm{hPa}$ wind (vectors, units: $\mathrm{m} . \mathrm{s}^{-1}$ ) of (a) the light precipitation events,(c) the extreme precipitation events, the filled areas indicate pass the $90 \%$ significance level. Composite of $200 \mathrm{hPa}$ GPH (contour, units: gpm, only show more than or equal to $12480 \mathrm{gpm}$, which indicates the South Asian high) and $200 \mathrm{hPa}$ zonal wind (shaded, units: $\mathrm{m}^{-\mathrm{s}^{-1}}$ ) of (b) the light precipitation events, (d) the extreme precipitation events. (e) the difference of $500 \mathrm{hPa}$ GPH (contours, units: gpm), its anomaly (shaded, units: gpm) and $700 \mathrm{hPa}$

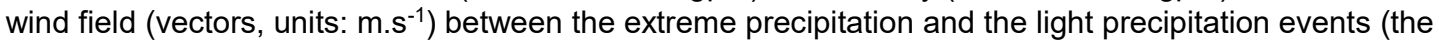
extreme precipitation events minus the light precipitation events), (f) the difference of GPH (shaded,

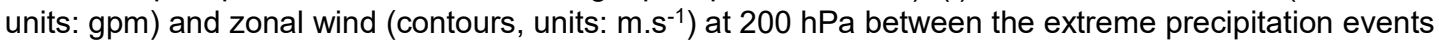
and the light precipitation events, the green lines are the zonal wind which is greater than or equal to 30 $\mathrm{m} . \mathrm{s}^{-1}$ for summer climate state. 


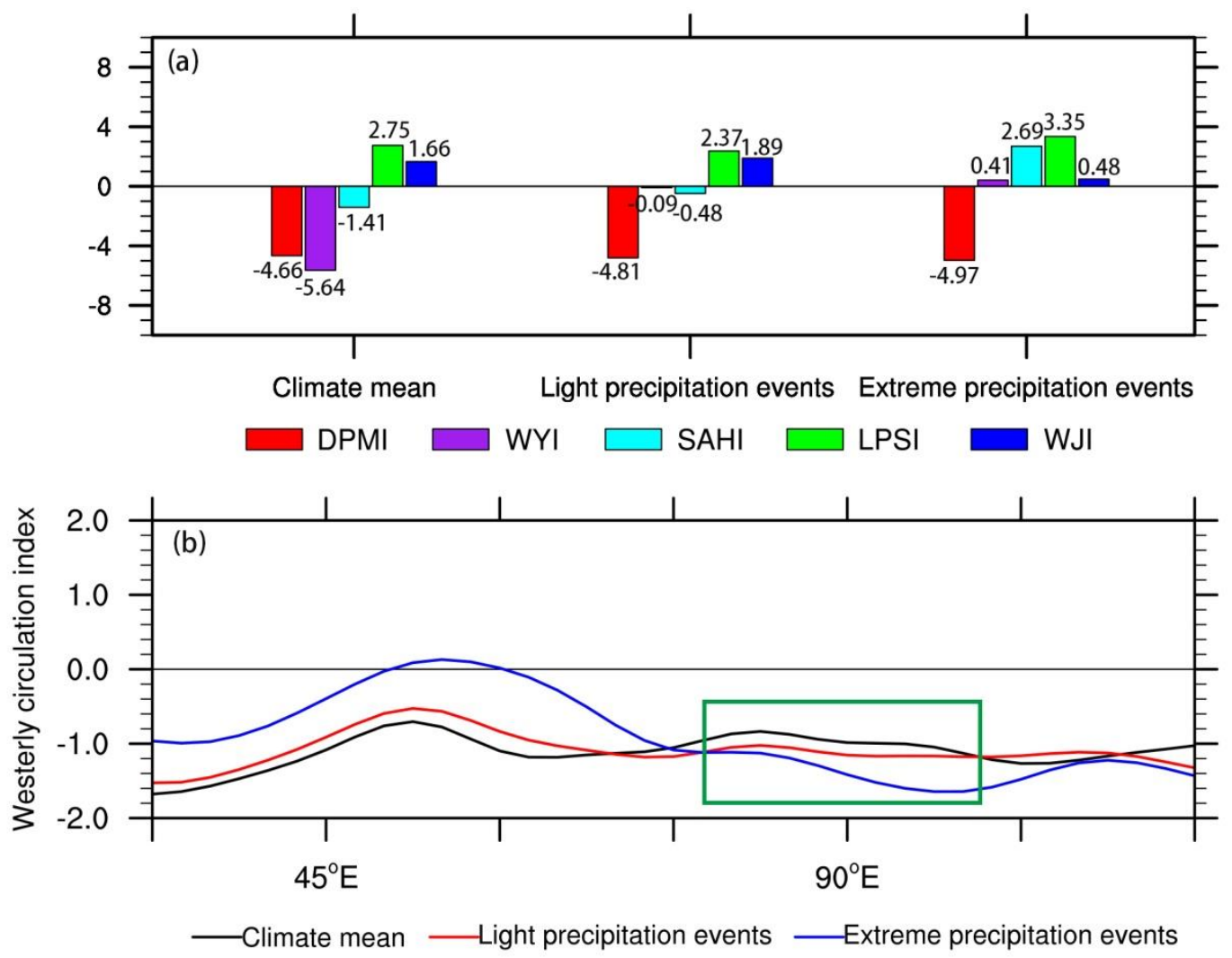

Fig.8 (a) Dynamic indices for the plateau monsoon (DPMI, red bar,units:10 $0^{-6} \cdot \mathrm{s}^{-1}$ ), South Asian summer monsoon (WYI, purple bar, normalized), South Asian high (SAH,cyan bar, normalized), low pressure system in the QB (LPSI, green bar,units: $10^{-6} \cdot \mathrm{m} \cdot \mathrm{s}^{-1}$ ) and westerly jet stream (WJI, blue bar, normalized),

(b) the meridional variation of normalized westerly circulation index $(\mathrm{WCI})$ in different situations. 

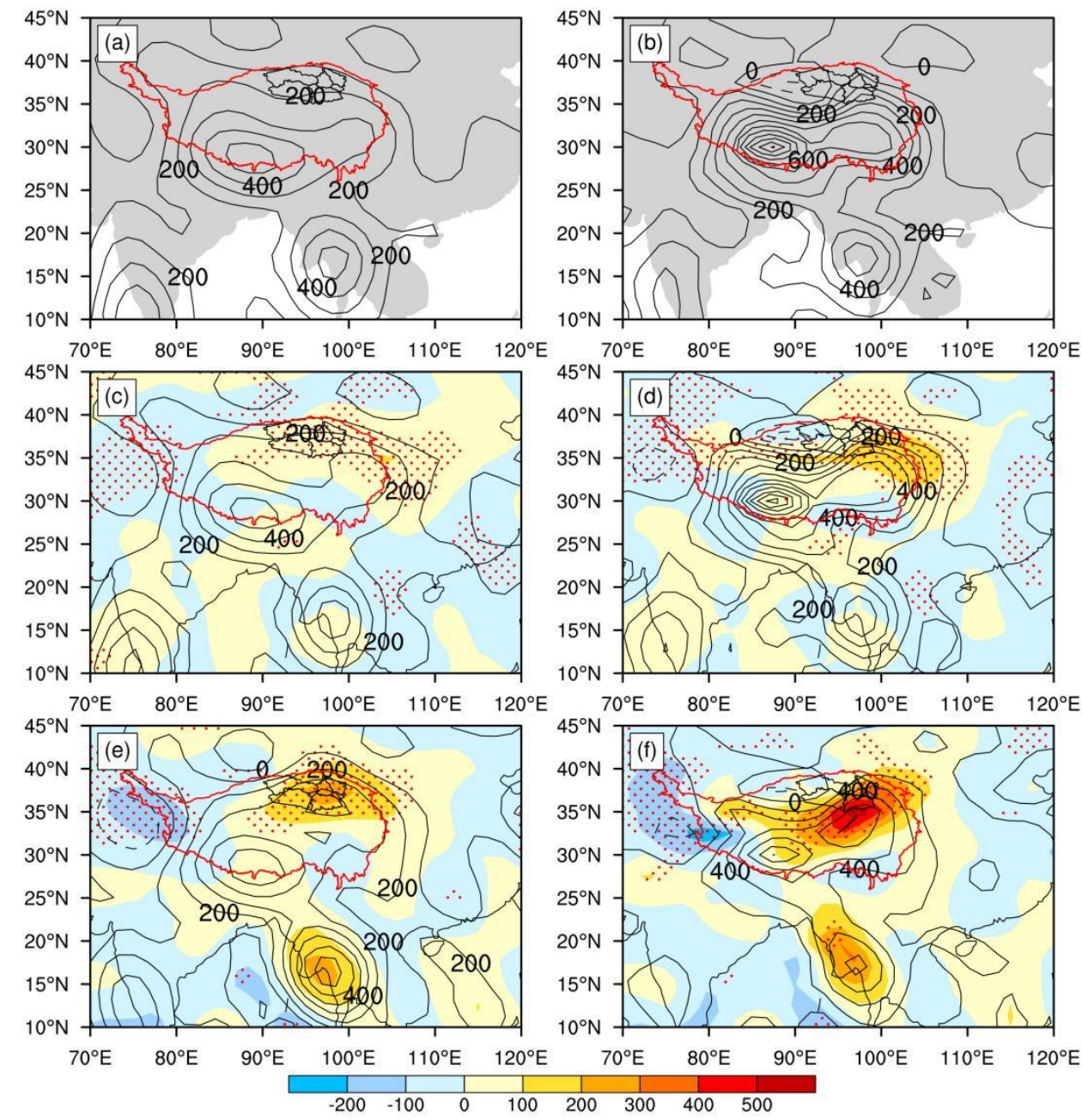

Fig.9 The spatial distribution of vertically integrated of apparent heat source $\left(<Q_{1}>\right)$ and apparent moisture sink $\left(<Q_{2}\right\rangle$ ), and their anomaly (shaded) (units:W. $\left.\mathrm{m}^{-2}\right)$, the left panel is apparent heat source $\left.\left(<Q_{1}\right\rangle\right)$ and it anomaly, the right panel is apparent moisture sink $\left.\left(<Q_{2}\right\rangle\right)$ and it anomaly, (a) and (b) indicate summer climate state, (b) and (c) indicate the light precipitation events, (e) and (f) indicate the extreme precipitation events, the red polygon indicates the TP, the same below, and the dotted areas indicate pass the $90 \%$ significance level. 


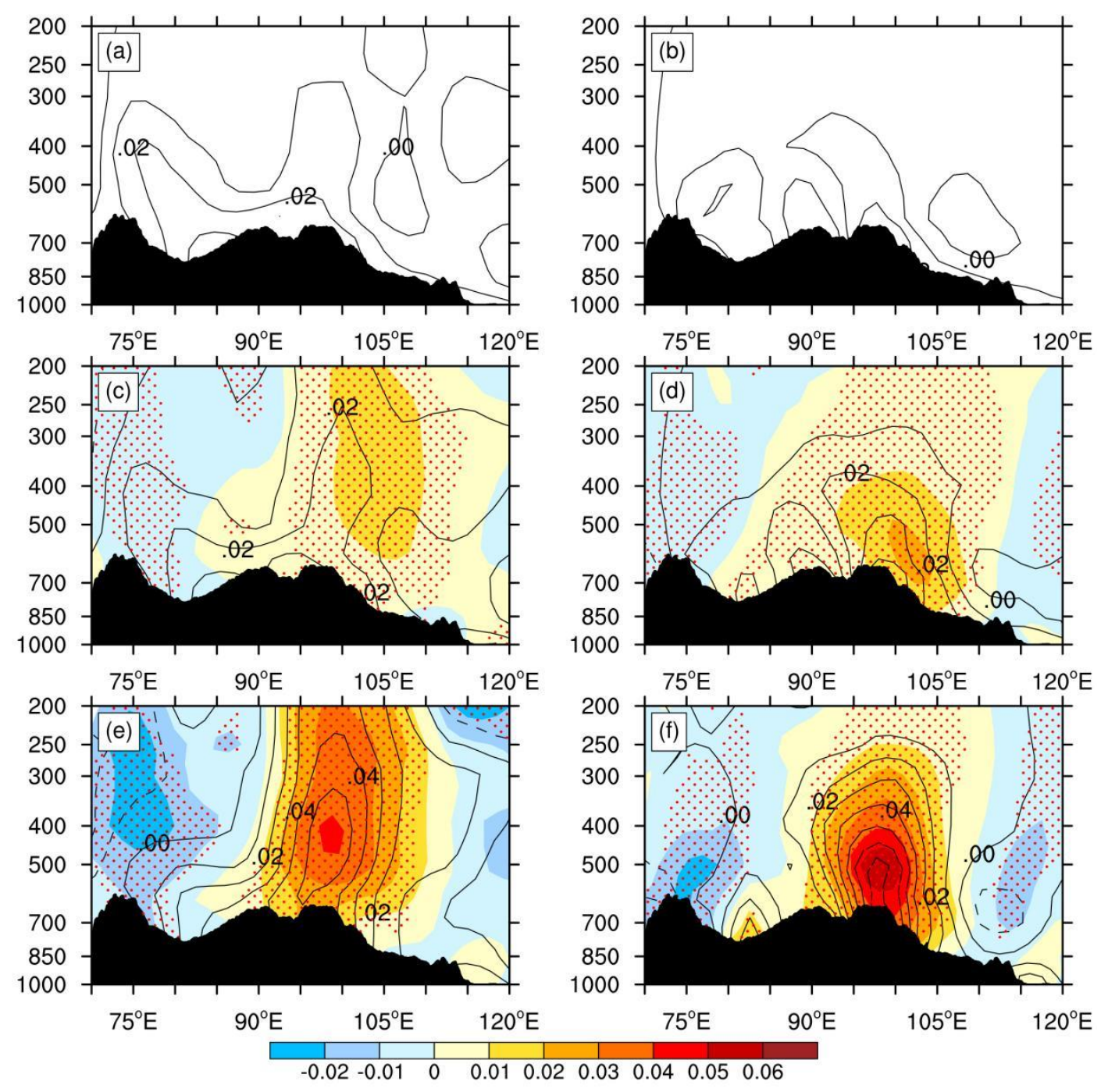

Fig.10 Pressure-meridional cross section of apparent heat source $\left(\mathrm{Q}_{1}\right)$, apparent moisture $\operatorname{sink}\left(\mathrm{Q}_{2}\right)$, and their anomaly (shaded) (Averaged over $35^{\circ} \mathrm{N} 40^{\circ} \mathrm{N}$, units: $\mathrm{m}^{2} . \mathrm{s}^{3}$ ), the left panel is apparent heat source $\left(Q_{1}\right)$ and it anomaly, the right panel is apparent moisture sink $\left(Q_{2}\right)$ and it anomaly, (a) and (b) indicate summer climate state, (b) and (c) indicate the light precipitation events, (e) and (f) indicate the extreme precipitation events, the black shaded is the averaged altitude from $35^{\circ} \mathrm{N}$ to $40^{\circ} \mathrm{N}$, and the dotted areas indicate pass the $90 \%$ significance level. 

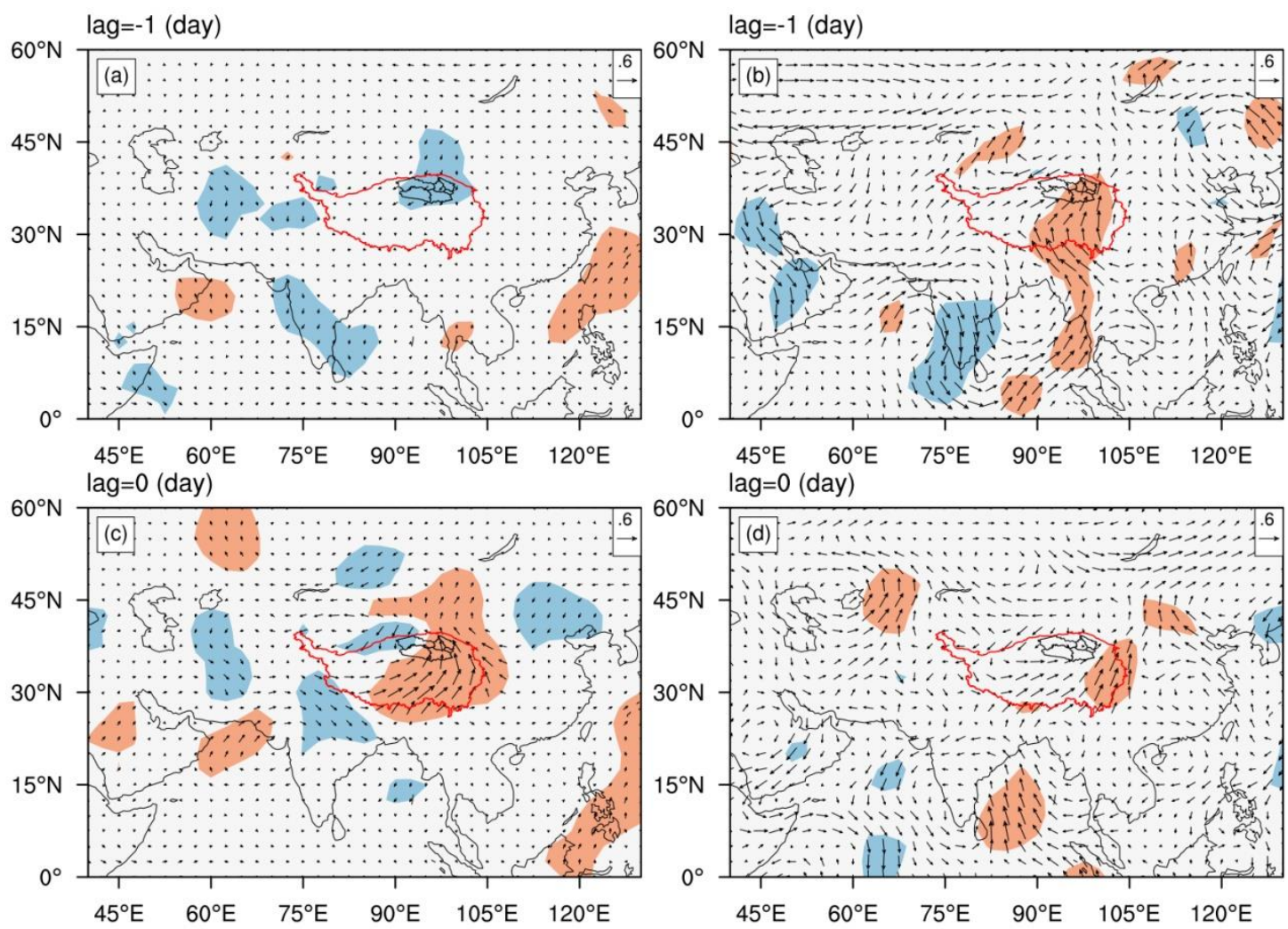

Fig.11 The spatial distribution of cross correlation vector between atmospheric apparent heat source $(<$ $\mathrm{Q}_{1}>$ ) (averaged over 35은 $\mathrm{N} \sim 0^{\circ} \mathrm{N}, 90^{\circ} \mathrm{E} \sim 100^{\circ} \mathrm{E}$ ) and the whole column moisture flux (uq and vq), lag=-1 day indicates the apparent heat source is a day ahead of moisture, (a) and (c) indicate the light precipitation events,(b) and (d) indicate the extreme precipitation events, the light-red (light-blue) shade indicates the positive (negative) areas that passed the $90 \%$ significance level. 

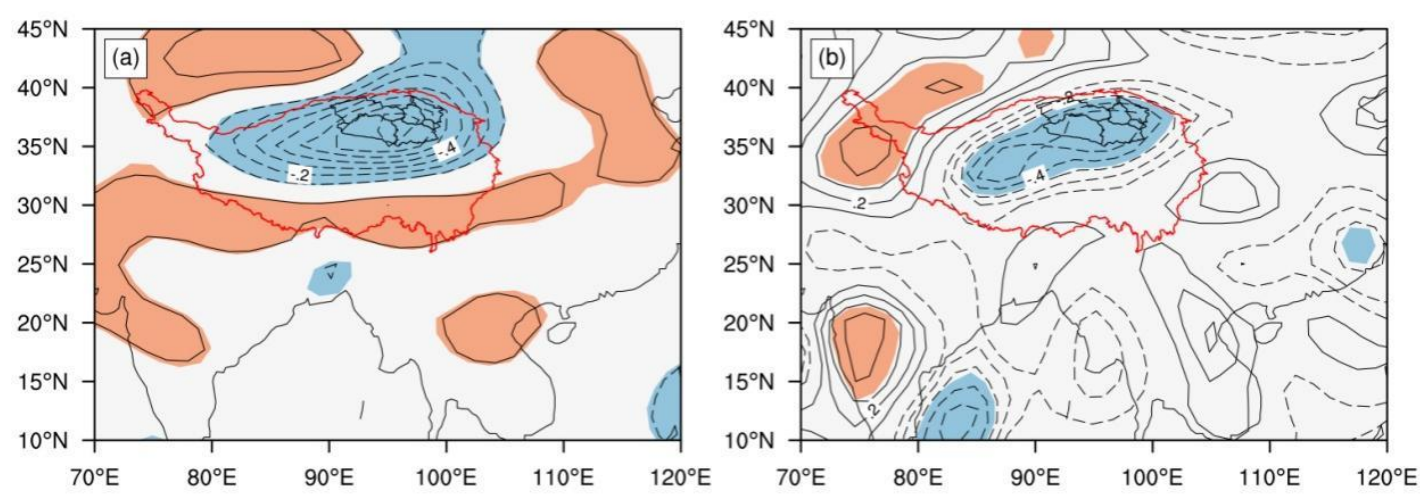

Fig.12 The spatial distribution of correlation vector between omega at 500hPa and atmospheric apparent heat source $\left(<\mathrm{Q}_{1}\right\rangle$ ) (averaged over $\left.35^{\circ} \mathrm{N} \sim 40^{\circ} \mathrm{N}, 90^{\circ} \mathrm{E} \sim 100^{\circ} \mathrm{E}\right)$, (a) the light precipitation, (b) the extreme precipitation events, the light-red (light-blue) shade indicates the positive (negative) areas that passed the $90 \%$ significance level. 


\section{Supplementary Files}

This is a list of supplementary files associated with this preprint. Click to download.

- supplementaryinformation.docx 